\title{
Selectivity Landscape of 100 Therapeutically Relevant GPCR Profiled by an Effector Translocation-Based BRET Platform
}

Charlotte Avet ${ }^{1,7}$, Arturo Mancini ${ }^{2,7}$, Billy Breton, ${ }^{2,8,9}$, Christian Le Gouill1,8, Alexander S. Hauser $^{3,8}$, Claire Normand ${ }^{2}$, Hiroyuki Kobayashi ${ }^{1}$, Florence Gross ${ }^{2}$, Mireille Hogue ${ }^{1}$, Viktoriya Lukasheva $^{1}$, Sandra Morissette ${ }^{2}$, Eric Fauman ${ }^{4}$, Jean-Philippe Fortin ${ }^{5}$, Stephan Schann ${ }^{6}$, Xavier Leroy ${ }^{6 *}$, David E. Gloriam ${ }^{3 *}$, and Michel Bouvier ${ }^{1,10^{*}}$.

${ }^{1}$ Institute for Research in Immunology and Cancer (IRIC), and Department of Biochemistry and Molecular Medicine, Université de Montréal; Montréal, Québec, H3T 1J4, Canada;

${ }^{2}$ Domain Therapeutics North America; Montréal, Québec, H4S 1Z9, Canada;

${ }^{3}$ Department of Drug Design and Pharmacology; University of Copenhagen; 2100 Copenhagen, Denmark;

${ }^{4}$ Internal Medicine Research Unit; Pfizer Worldwide Research, Development and Medical; Cambridge, MA 02139, USA;

${ }^{5}$ Pfizer Global R\&D; Cambridge, MA 02139, USA;

${ }^{6}$ Domain Therapeutics; 67400 IIlkirch-Strasbourg, France;

${ }^{7}$ These authors contributed equally;

${ }^{8}$ These authors contributed equally;

${ }^{9}$ Current address: Institute for Research in Immunology and Cancer (IRIC), Université de Montréal; Montréal, Québec, H3T 1J4, Canada;

${ }^{*}$ Co-senior authors;

${ }^{10}$ Lead Contact.

\section{* Co-senior Authors:}

Michel Bouvier ; IRIC, Université de Montréal : michel.bouvier@umontreal.ca,

David E. Gloriam; University of Copenhagen: david.gloriam@sund.ku.dk,

Xavier Leroy; Domain Therapeutics : xleroy@domaintherapeutics.com. 


\section{SUMMARY}

The ability of individual G protein-coupled receptors (GPCR) to engage multiple signaling pathways opens opportunities for the development of better drugs. This requires new knowledge and tools to determine the $\mathrm{G}$ protein subtypes and $\beta$ arrestins engaged by a given receptor. Here, we used a new BRET-based effector membrane translocation assay (EMTA) that monitors activation of each $\mathrm{G} \alpha$ protein through the recruitment of selective $\mathrm{G}$ protein effectors and Barrestins to the plasma membrane. Profiling of 100 therapeutically relevant GPCR revealed a great diversity of coupling profiles with some receptors displaying exquisite selectivity, whereas others promiscuitely engage all four $\mathrm{G}$ protein families. Comparison with existing datasets points to commonalities but also to critical differences between studies. Combining a biosensor subset allowed detecting activity of nearly all GPCR thus providing a new tool for safety screens and systems pharmacology. Overall, this work describes unique resources for studying GPCR function and drug discovery.

\section{KEYWORDS}

G protein-coupled receptor (GPCR), enhanced bystander bioluminescence resonance energy transfer (ebBRET), Biosensor, Effector membrane translocation assay (EMTA), Highthroughput assay, G protein activation, Functional selectivity, Systems pharmacology. 


\section{INTRODUCTION}

G protein-coupled receptors (GPCR) play crucial roles in the regulation of a wide variety of physiological processes and represent one-third of clinically prescribed drugs (Hauser et al., 2017; Sriram and Insel, 2018). However, currently approved drugs only target $\sim 16 \%$ of known GPCR (Hauser et al., 2020). Consequently, there is a need to develop innovative approaches to increase our knowledge incorporating novel GPCR biology and pharmacology to increase the druggable landscape.

Until recently, GPCR-mediated signal transduction was believed to rely on linear signaling pathways whereby a given GPCR selectively engages a single heterotrimeric $(\alpha \beta \gamma)$ G protein family, defined by the nature of its $\mathrm{G} \alpha$ subunit (Oldham and Hamm, 2008). Ga proteins are divided into four major families $\left(G_{s}, G_{i / o}, G_{q / 11}\right.$, and $\left.G_{12 / 13}\right)$ encoded by 16 human genes (Milligan and Kostenis, 2006). Once activated, these proteins each engage different downstream effectors that ultimately produce different signaling (and biological) outcomes (Wettschureck and Offermanns, 2005). However, it has become clear that many GPCR can engage more than one $G$ protein family and that ligands can selectively promote the engagement of different subsets of these pathways (Azzi et al., 2003; Kenakin, 2019; Namkung et al., 2018; Quoyer et al., 2013; Smith et al., 2018). This concept, known as functional selectivity or ligand-biased signaling, represents a promising avenue for GPCR drug discovery since it offers the opportunity to preferentially activate signaling pathways important for therapeutic efficacy while minimizing undesirable side effects by avoiding activation of other pathways (Galandrin et al., 2007; Kenakin, 2019; Stallaert et al., 2011). In addition, once believed to simply mediate receptor desensitization and internalization, Barrestins are now recognized as key signaling hubs acting downstream of GPCR (Luttrell et al., 2018).

To fully explore the potential of functional selectivity in drug discovery and development, it becomes essential to have an exhaustive description of the effectors that can be engaged by a given receptor, providing receptor- and ultimately ligand-specific signaling signatures. Also, a better understanding of the coupling determinants underlying the selectivity of GPCR 
toward different subsets of $\mathrm{G}$ protein subtypes and $\beta$ arrestins requires a broad coverage of the signaling landscape of each receptor.

Here, we describe a unique assay platform that does not require modification of receptors or G proteins for interrogating the signaling profiles of GPCR in response to their endogenous or prototypical ligands. We used 15 pathway-selective enhanced bystander bioluminescence resonance energy transfer (ebBRET) biosensors monitoring the translocation of downstream effectors to the plasma membrane upon $\mathrm{G}$ protein activation and ßarrestin engagement. Over 1,500 concentration response curves were generated for 100 therapeutically relevant GPCR, revealing a great diversity in the coupling selectivity of the studied receptors. Using a subset of the biosensor collection provides a nearly universal GPCR activity detection system useful for safety and system pharmacology studies. Overall the new ebBRET-based effector membrane translocation assay (EMTA) offers a platform to study GPCR activation and selectivity on a large scale for drug discovery and mechanistic studies. In addition, our data provides a rich source of information to explore the principles underlying receptor/G protein coupling selectivity relationships. 


\section{RESULTS}

\section{ebBRET-based Effector Membrane Translocation Assay (EMTA) Allows Detection of Each}

\section{Ga Protein Subunit Activation and Barrestin Recruitment}

In order to establish the signaling repertoire of a large number of GPCR, we developed a high-throughput biosensor platform based on ebBRET (Namkung et al., 2016) to monitor the activation of each $\mathrm{G} \alpha$ protein, as well as Barrestin 1 and 2 recruitment to the plasma membrane (PM). To measure $G \alpha_{s}$ protein engagement, we took advantage of the fact that $\mathrm{G \alpha}_{\mathrm{s}}$ dissociates from the PM following activation (Wedegaertner et al., 1996). In this configuration, the energy donor (Renilla luciferase; Rlucll), is directly fused to $\mathrm{Ga}_{\mathrm{s}}$ while the energy acceptor (Renilla green fluorescent protein; rGFP) is anchored to the PM via a CAAX motif (rGFP-CAAX) (Namkung et al., 2016). Gas activation upon GPCR stimulation leads to a reduction in the ebBRET signal, reflecting its dissociation from the PM (Figure 1A). To detect the activation of the other Ga subtypes, we engineered a new generation of ebBRET-based sensors, the EMTA ebBRET biosensor platform, monitoring the PM recruitment of effector proteins selectively interacting with active $G \alpha$ subunits (Figure 1B). For this purpose, the sub-domains of effector proteins selectively interacting with activated $G_{q / 11}, G_{i / o}$ or $G_{12 / 13}$ were fused at their C-terminus to Rlucll and co-expressed with different untagged receptor and Ga protein subtypes. Upon GPCR activation, these energy donors translocate to the PM to bind activated (GTP-bound) Ga proteins, bringing them in close proximity to the PMlocalized rGFP-CAAX and leading to an increase in ebBRET. This new generation of sensors presents the advantage of not requiring modification of the $G$ proteins nor the receptors. The same PM translocation principle is used to measure $\beta$ arrestin recruitment (Figure 1C) (Namkung et al., 2016).

To validate these biosensors, we used a subset of GPCR known to activate specific G $\alpha$ subtypes in the absence or presence of pharmacological inhibitors or using engineered cells lacking selective $\mathrm{G} \alpha$ subtypes. The bile acid receptor GPBA was chosen for validation of the $\mathrm{G}_{\mathrm{s}}$ activation biosensor (Kawamata et al., 2003) and as expected, lithocholic acid stimulation of GPBA expressing-cells resulted in increased CAMP production revealed by a decrease in BRET signal using a BRET²-based EPAC biosensor (Barak et al., 2008; Leduc et al., 2009) (Figure 2A, left panel). The activation of GPBA also led to a decrease in the ebBRET signal between $\mathrm{Ga}_{\mathrm{s}}$-Rlucll and rGFP-CAAX (Figure 2A, right panel, black curve). To confirm 
that the loss of $G \alpha_{s}$ PM localization resulted from its activation, we used cholera toxin (CTX) to directly activate $\mathrm{Ga}_{\mathrm{s}}$ (De Haan and Hirst, 2004). Treatment with CTX led to a substantial decrease in ebBRET signal with the Gas sensor (CTX; Figure 2A, central panel), confirming the link between an ebBRET decrease and $\mathrm{Ga}_{\mathrm{s}}$ activation. As shown in Figure $2 \mathrm{~A}$ (right panel), the dose-dependent decrease in ebBRET signal following GPBA activation was not affected neither by the $G_{q / 11}$-selective inhibitors UBO-QIC (also known as FR900359) (Schrage et al., 2015), nor the inactivation of $\mathrm{G}_{\mathrm{i} / \mathrm{o}}$ family members using pertussis toxin (PTX), confirming the selectivity of this assay to selectively detect $\mathrm{G}_{\mathrm{s}}$ activation.

For the $G_{i / o}$ family members, the dopamine $D_{2}$ receptor was used to validate the ability of the $\mathrm{G}_{\mathrm{i} / \mathrm{o}}$ binding domain of the effector Rap1 GTPase-activating protein 1 (Rap1GAP) (Jordan et al., 1999; Meng and Casey, 2002; Meng et al., 1999) to selectively detect $G_{i / o}$ activation. The dopamine-promoted increase in ebBRET signal between Rap1GAP-Rlucll and rGFP-CAAX in the presence of different $\mathrm{G}_{\mathrm{i} / \mathrm{o}}$ subunits is not affected by UBO-QIC (Figure 2B, left panel), whereas PTX completely blocked it for all members of $G \alpha_{i / o}$ family except for $G \alpha_{z}$, known to be insensitive to PTX (Casey et al., 1990) (Figure 2B, right panel). Altogether, these results confirmed the selectivity of the sensor for the activation of the $\mathrm{G}_{\mathrm{i} / \mathrm{o}}$ protein family.

For the $G_{q / 11}$ family members, the gonadotropin-releasing hormone receptor ( $G n R H R$ ) was used to validate the ability of the $G_{q / 11}$ binding domain of the effector p63 Rho guanine nucleotide exchange factor (p63RhoGEF) (Lutz et al., 2007; Rojas et al., 2007) to selectively detect $\mathrm{G}_{\mathrm{q} / 11}$ activation. The $\mathrm{GnRH}$-promoted increase in ebBRET signal between p63RhoGEFRlucll and rGFP-CAAX in the presence of different $G \alpha_{q / 11}$ subunits is not affected by PTX (Figure 2C, right panel), whereas UBO-QIC completely blocked it for all members of $\mathrm{G}_{\mathrm{q} / 11}$ family except for $\mathrm{G}_{15}$, known to be insensitive to UBO-QIC (Schrage et al., 2015) (Figure 2C, left panel). These data demonstrate the usefulness of the p63RhoGEF-Rlucll/rGFP-CAAX pair to measure the activation of the $\mathrm{G}_{\mathrm{q} / 11}$ family members.

For the $\mathrm{G}_{12 / 13}$ family members, the cannabinoid receptor type 1 ( $\left.C B_{1}\right)$, for which $G_{12 / 13}$ coupling was confirmed using the RhoA effector of Protein Kinase N1-based biosensor (PKNRBD-Rlucll/rGFP-CAAX) (Namkung et al., 2018) (Figure 2D, top left panel), was used to validate the ability of the $\mathrm{G}_{12 / 13}$ binding domain of the effector PDZ-RhoGEF (Fukuhara et al., 
2001; Tanabe et al., 2004) to selectively detect $\mathrm{G}_{12 / 13}$ activation. The WIN-55,212-2promoted increase in ebBRET signal between PDZ-RhoGEF-Rlucll and rGFP-CAAX was not affected neither by UBO-QIC (Figure 2D, bottom left panel), nor PTX (Figure 2D, bottom right panel). Given the lack of known $\mathrm{G}_{12 / 13}$ pharmacological inhibitors, we took advantage of a genetic tool to demonstrate the role of $\mathrm{G}_{12 / 13}$ activation in the PDZ-RhoGEF-Rlucll/rGFPCAAX BRET signal. WIN-55,212-2 promoted an ebBRET increase in HEK293 cells genetically deleted for $\mathrm{G \alpha}_{12}$ and $\mathrm{G} \alpha_{13}$ proteins $\left(\Delta \mathrm{G}_{12 / 13}\right.$ ) (Devost et al., 2017; Namkung et al., 2018) only following reintroduction of either $\mathrm{G \alpha}_{12}\left(\Delta \mathrm{G}_{12 / 13}+\mathrm{G}_{12}\right)$ or $\mathrm{G \alpha}_{13}\left(\Delta \mathrm{G}_{12 / 13}+\mathrm{G}_{13}\right)$ (Figure 2D, top right panel).

Real-time recruitment of the different effectors (Rap1GAP-Rlucll, p63-RhoGEF-Rlucll and PDZ-RhoGEF-Rlucll) to the PM upon receptor activation was detected by ebBRET imaging as illustrated in Video 1-3 and the ability of the EMTA platform to monitor time-dependent activation of the different $\mathrm{G} \alpha$ subtypes is illustrated in Figure S1.

\section{Signaling Signatures of One Hundred Therapeutically Relevant Receptors Reveal a High Diversity of Coupling Selectivity Between G Protein Families}

We used the above ebBRET-based biosensor platform to assess the signaling signature of 100 therapeutically relevant human GPCR belonging to class A (85\%), B (10\%) and C (5\%). For each receptor, we evaluated its ability to activate 15 pathways, including $G \alpha_{s}, G \alpha_{i 1}, G \alpha_{i 2}$,

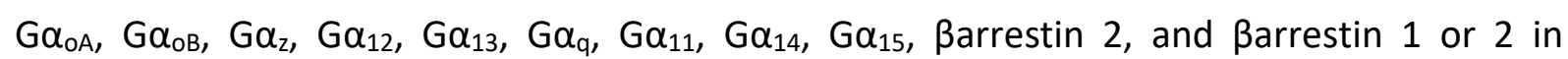
presence of GRK2, in response to increasing concentrations of either physiological or pharmacological prototypical agonists. $E_{\max }$ and $\mathrm{pEC}_{50}$ values were determined (Data $\mathbf{S 1}$ and Table S1) and, based on our pre-determined threshold criteria (STAR Methods), agonistdependent activation was assigned to each signaling pathway. These signaling signatures for each GPCR have been summarized using radial graph representations (Figure S2). Since some receptors have detectable endogenous expression, the ligand-promoted responses observed for overexpressed receptors could be distorted by endogenous responses from receptors that can also respond to the ligand used. To exclude such false positive responses, we also checked for the agonist-promoted response obtained in parental HEK293 cells and we excluded the responses that were not linked to the overexpressed receptor (Figure S3). 
In order to compare the signaling efficiency obtained for the 100 GPCR across all receptors and pathways and to overcome differences in receptor expression levels, we first normalized $E_{\max }$ and $\mathrm{pEC}_{50}$ values (between 0 and 1 ) deduced from concentration-response curves across receptors as a function of a reference receptor yielding the largest response for a given pathway (Figure 3A, left panel). Then, these values were normalized between 0 and 1 for the same receptor across pathways, using the pathway with the largest response for this receptor as the reference (Figure $\mathbf{3 A}$, right panel). This evaluation of coupling efficiency for each receptor is summarized as heatmap representations (Figure 3B) that reveals a high diversity of signaling profiles. This is particularly evident when considering the efficacy $\left(E_{\max }\right)$. To better appreciate the different levels of functional selectivity across receptors, we determined the numbers of receptors showing overlap between $G$ protein family coupling (Figure 4A-B). $17 \%$ of the receptors coupled to only one subtype family, whereas others displayed more promiscuity by coupling to 2,3 or $4 \mathrm{G}$ protein families $(39 \%, 35 \%$ and $9 \%$ of receptors, respectively; Figure $\mathbf{4 B}$ and $\mathbf{4 C}$ ). Receptors coupling to a single $\mathrm{G}$ protein family favored the members of the $\mathrm{G}_{\mathrm{i} / \mathrm{o}}$ family. Indeed, $16 \%$ of the receptors coupling to $\mathrm{G}_{\mathrm{i} / \mathrm{o}}$ only engaged this subtype family in comparison to $0,2.4$ and $3 \%$ for receptors activating $\mathrm{G}_{12 / 13}$, $G_{q / 11}$ and $G_{s}$, respectively. This indicates that receptors engaging members of these 3 families tend to be more promiscuous in their coupling ability.

When examining the frequency of coupling for each $G \alpha$ subunit (Figure 4D), the $G_{i / o}$ family members were the most commonly activated, going from 73 to $85 \%$ of the receptors for $\mathrm{Ga}_{z}$ and $\mathrm{G \alpha}_{\mathrm{OB}}$, respectively. In contrast, only 33,18 to 30 and 37 to $45 \%$ of the receptors engaged $\mathrm{G}_{\mathrm{s}}, \mathrm{G}_{12 / 13}$ and $\mathrm{G}_{\mathrm{q} / 11}$ (excluding $\mathrm{Ga}_{15}$ ) family members, respectively. Not surprisingly, as it is frequently considered as a promiscuously coupling $G$ protein subtype, $G \alpha_{15}$ was found to be activated by $81 \%$ of the receptors. Interestingly, $45 \%$ of the receptors activating the full set of $G_{q / 11}$ family (including $G \alpha_{15}$ ) only activate the $G \alpha_{15}$ subunit (Figure $S 4 A$ ), confirming that it is an outlier within this subtype family.

When considering ßarrestin recruitment to the PM upon receptor stimulation, our analysis shows that $22 \%$ of receptors did not recruit Barrestin beyond the established threshold, even in the presence of overexpressed GRK2, which is known to favor recruitment (Ehrlich et al., 2019) (Figure 4E). Among the receptors able to recruit $\beta$ arrestins, only a very small 
number of receptors selectively recruited either Barrestin1 (1.3\%) or Barrestin2 (6.4\%), most of them recruiting both ßarrestin subtypes in the presence of GRK2 (92.3\%) (Figure 4E). Overexpression of GRK2 potentiated the recruitment of Barrestin2 for $68 \%$ of receptors, as mainly observed by an increase in the $E_{\max }$, highlighting the importance of GRK2 expression level in determining the engagement of $\beta$ arrestin (Data S1 and Table S1).

\section{Receptors Show an Unexpected Level of Coupling Selectivity Between Members of the Same G protein Family}

In addition to the selectivity towards the different subtype families, preferential engagement of distinct members within a subtype family was observed (Figure S2). For instance, 33\% of $\mathrm{G}_{\mathrm{i} / \mathrm{o}}$-coupled receptors can engage only a subpopulation of the family (Figure S4A). For the $\mathrm{G}_{\mathrm{q} / 11}$ family, only $44 \%$ engaged all family members with $45 \%$ engaging only $\mathrm{Ga}_{15}$ and $11 \%$ engaging only 2 or 3 members of the family.

Globally, we assessed whether the receptor/G protein coupling profile similarities could be correlated with the $\mathrm{G} \alpha$ protein sequence identity using pairwise comparison (Figure 5A). The comparison was performed using either the full-length $G$ protein sequences or particular domains important for their activity including the $\mathrm{H} 5$ domain that penetrates into the receptor cavity, the 7 last amino acid of $\mathrm{H} 5$ domains used by Inoue et al. to create their G protein chimeras for $G$ protein profiling (Inoue et al., 2019) and the G protein barcode proposed by Flock et al. as the determinant underlying selective $\mathrm{G}$ protein coupling (Flock et al., 2017). Reasonable correlations were observed in all cases with the highest correlation observed for the $\mathrm{H} 5$ domain and the G protein barcode $\left(r^{2} \geq 0.80\right)$ and the lowest with 7 last amino acid of $\mathrm{H} 5\left(r^{2}=0.65\right)$. This indicate that receptors tend to couple to $\mathrm{G} \alpha$ subunits that share the greatest percent sequence identity between their $\mathrm{H} 5$ domains.

To assess the possible functional proximity toward the different pathways activated by the 100 GPCR, pairwise correlation between the coupling efficiency (double-normalized $E_{\max }$ ) for each pathway was performed using Pearson standard correlation coefficient (Figure 5B). As expected, the highest level of correlation was observed within $G$ protein families. One notable exception is $\mathrm{G \alpha}_{15}$ that was found to have a great propensity to be engaged by receptors also activating $G_{s}$, which was not the case for the members of its evolutionary 
closest family, the $G_{q / 11}$ clad (Figure $4 A$ ). This may indicate that $G \alpha_{15}$ forms a family on its own. When comparing the different families, the $G_{q / 11}$ family correlated the strongest to the $\mathrm{G}_{12 / 13}$ family, whereas the $\mathrm{G}_{\mathrm{s}}$ family is strongly negatively correlated to the $\mathrm{G}_{\mathrm{i} / \mathrm{o}}$ family. Finally, the two ßarrestins cluster together and their engagement was best correlated with $\mathrm{G \alpha}_{15}, \mathrm{G \alpha}_{\mathrm{z}}$ and $\mathrm{G} \alpha_{\mathrm{oB}}$. Similar conclusions can be drawn from a matrix expressing the \% of receptors engaging a specific $\mathrm{G} \alpha$ subtype that also activated another subtype, as illustrated in Figure S4B.

When considering the correlation within the same family, whereas the correlation was very strong among all members of the $\mathrm{G}_{\mathrm{q} / 11}$ family (except for $\mathrm{G \alpha}_{15}$ ) there is more variation within the $G_{i / o}$ family members. The correlation is the strongest between $G \alpha_{o B}$ and either $G \alpha_{o A}$ or $G \alpha_{z}$, and the weakest between $G \alpha_{i 1}$ and $G \alpha_{z}$. Such striking examples of these intra-family coupling selectivity includes the $5-\mathrm{HT}_{2 B}, \mathrm{MC} 3 \mathrm{R}$ and $\mathrm{H}_{2}$ receptors that engage only $\mathrm{G}_{\mathrm{oB}}$ and $G \alpha_{z}$ or the FP and $Y_{5}$ receptors that activate only $G \alpha_{o B}, G \alpha_{O A}$ and $G \alpha_{z}$. An example of extreme selectivity is GPR65 that exclusively engages $\mathrm{Ga}_{\mathrm{oB}}$.

\section{Comparison with Previous Datasets Reveals Commonalities and Crucial Differences}

We compared the signaling profiles that we observed using the EMTA platform with that of the chimeric $\mathrm{G}$ protein-based assay developed by Inoue et al. (Inoue et al., 2019) and the Guide to Pharmacology database (GtoPdb; https://www.guidetopharmacology.org/). Among the 100 receptors that we tested, 71, 96 and 69 are shared with the Inoue, GtoPdb and both resources, respectively (Figure 6A). As illustrated in Figure 6B, the general relative distributions of $\mathrm{G}$ protein coupling observed are relatively similar across datasets. However, a closer comparison of the $\mathrm{G}$ protein subtypes found to be activated in the Inoue's study vs. our study for the common subtypes tested reveals interesting differences (Figure 6C). Receptors found to activate $G \alpha_{s}, G \alpha_{i 1}, G \alpha_{q}, G \alpha_{12}$, or $G \alpha_{13}$ showed the best overlap between the two studies with $73-77 \%$ of congruence. Among the common 71 receptors tested, a smaller number were found to couple to $G \alpha_{s}\left(20\right.$ vs. 28), $G \alpha_{i 1}$ (56 vs. 58), $G \alpha_{q}$ (33 vs. 36), $G \alpha_{12}$ (15 vs. 22) and $\mathrm{Ga}_{14}$ (37 vs. 42), in our study vs. Inoue's. In contrast we detected more receptors activating $\mathrm{Ga}_{13}$ (23 vs. 17). The greatest difference between the two studies is observed for receptors coupling to $G \alpha_{o}(61$ vs. 43$)$ and $G \alpha_{z}(53$ vs. 39) and the most dramatic one being observed for $\mathrm{G \alpha}_{15}$ (63 vs. 17). 
When comparing the 69 receptors shared between the three datasets (Figure S5), the greatest similarity is observed for the $\mathrm{G}_{\mathrm{i} / \mathrm{o}}$ with only one receptor reported in $\mathrm{GtoPdb}$ as $\mathrm{G}_{\mathrm{i} / \mathrm{o}}$ but not found in the combined studies ( 3 were not found in our study and 4 in Inoue's). The combined studies also identified a total of 8 receptors that had not been reported in GToPdb

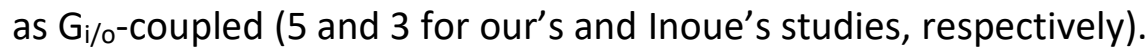

For the receptors reported as $\mathrm{G}_{\mathrm{s}}$ coupling in the GtoPdb, 7 were not found by the combined studies ( 8 vs. 9 for our's and Inoue's studies, respectively). The pan-G protein studies also identified a total of 11 receptors that had not been reported as $G_{s}$ coupled ( 1 and 10 for our's and Inoue's studies, respectively).

For the receptors reported as $\mathrm{G}_{12 / 13}$ coupling in the $\mathrm{GtoPdb}$, only one was not found by the combined pan-G protein studies. The experimental studies also identified a total of 21 receptors that had not been reported as $\mathrm{G}_{12 / 13}$-coupled (11 and 10 for our's and Inoue's studies, respectively). This relatively large discrepancy with the GtoPdb is most likely due to the lack of robust assays to monitor $\mathrm{G}_{12 / 13}$ activation that were available until recently (Quoyer et al., 2013; Schrage et al., 2015). To validate some of the new $\mathrm{G}_{12 / 13}$-coupled receptors identified in our study, we used a biosensor based on the recruitment of PKN to the plasma membrane (PKN-RBD-Rlucll/rGFP-CAAX) (Namkung et al., 2018) as a surrogate of RhoA activity, which is a well characterized downstream effector of $G_{12 / 13}$. As shown in Figure S6A, activation of both FP and CysLT 2 lead to the recruitment of PKN to the PM. The $\mathrm{G}_{\mathrm{q} / 11}$ inhibitor YM-254890 had no or marginal effects on the response (Figure S6A), excluding the possibility that it could originate from $\mathrm{G \alpha}_{\mathrm{q} / 11}$ that has been shown to activate RhoA under certain conditions, confirming that these receptors signal through $G \alpha_{12 / 13}$ proteins.

For the receptors reported as $\mathrm{G}_{\mathrm{q} / 11}$ coupling in the GtoPdb, only one was not identified by the combined pan-G protein studies ( 1 vs. 6 for our's and Inoue's studies, respectively). The combined studies identified 15 receptors that had not been reported as $G_{q / 11}$ (14 and 1 for

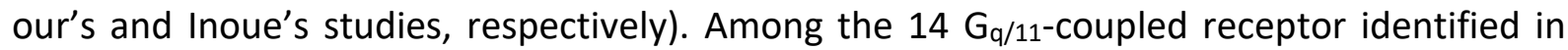
our screen, 11 only activate $G \alpha_{15}$ and no other members of the family. Hence, if we treat $\mathrm{Ga}_{15}$ subtypes apart from its phylogenetic family classification, the majority of receptors 


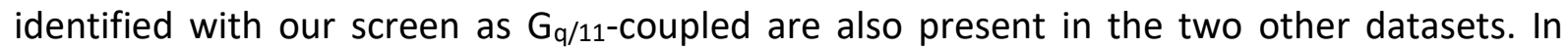
addition, our platform allowed the identification of $61 \mathrm{G \alpha}_{15}$ coupling receptors compared to 15 in Inoue et al. (Figure S5B). To validate some of the new $\mathrm{G}_{15}$-coupled receptors identified in our study, we took advantage of the lack of $\mathrm{Ga}_{15}$ in HEK293 cells and assessed the impact of $\mathrm{Ga}_{15}$ expression on receptor-mediated calcium responses (Figure S6B). For $\mathrm{EP}_{2}$ receptor that was found to couple to $G_{15}$ but no other member of the $G_{q / 11}$ family, $G \alpha_{15}$ significantly increased the PGE2-promoted calcium response. For the $\alpha_{2 A} A R$ and $V_{2}$ receptors that can couple other $G_{q / 11}$ family members, treatment with $Y M-254890$ completely abolished the agonist-promoted calcium response in the absence of $\mathrm{G \alpha}_{15}$ expression. In contrast, a calcium response was observed following expression of $\mathrm{G \alpha}_{15}$ and was completely insensitive to YM254890 (Figure S6B), confirming that these receptors can productively engage this YM254890-insensitive G protein subtype (Takasaki et al., 2004).

\section{Combining $G_{z}$ and $G_{15}$ Biosensors Provides a Useful Tool for Safety and Systems}

\section{Pharmacology by Detecting Nearly all GPCR Activation}

Analysis of G protein coupling for the 100 GPCR studied revealed that a vast majority of these receptors (95\%) activate either $\mathrm{G} \alpha_{z}(73 \%)$ or $\mathrm{G}_{15}$ (81\%). Accordingly, the creation of a biosensor capable of simultaneously measuring activation of both pathways would provide an almost universal sensor applicable to screening.

To this end, the $G_{z}$ and $G_{15}$ biosensors (Rap1GAP-Rlucll+G $\alpha_{z} / p 63-R h o G E F-R l u c l l+G \alpha_{15} / r G F P-$ CAAX) were combined into one assay and validated on a safety panel of 24 GPCR (Bowes et al., 2012). As shown in Figure S7, the 24 GPCR tested all engaged the $G_{z} / G_{15}$ biosensor in a ligand concentration-dependent manner. Its sensitivity was sufficient to detect ligandinduced activation of receptors largely or uniquely coupled to either $\mathrm{G \alpha}_{2}$ (e.g., $\mathrm{CB}_{2}$ ) or $\mathrm{Ga}_{15}$ (e.g., $A_{2 A}$ ), as well as receptors coupled (to varying degrees) to both pathways.

To test the usefulness of the $G_{z} / G_{15}$ sensor to detect off-target action, it was used to screen the activity of chosen ligands on the safety GPCR panel. As shown in Figure 7A, most ligands tested were specific for their primary target(s). Interestingly, certain ligands displayed unanticipated functional cross-reactivity with GPCR other than their cognate targets. These 
included the activation of the $C_{1}$ and $C B_{2}$ receptors by acetylcholine, $\alpha_{2 A} A R$ by dopamine and serotonin, and of the $D_{2}$ by noradrenaline and serotonin.

\section{EMTA Detects Off-Target and Cross-Talk GPCR Activation}

The safety panel data show that some ligands display polypharmacological profiles (i.e., ligands activated GPCR other than their cognate receptor). For example, noradrenaline and serotonin, which are natural ligands for adrenergic and serotoninergic receptors families, respectively, promoted $G_{z} / G_{15}$ activation in $D_{2}$-expressing cells. Moreover, dopamine and serotonin also activated $\alpha_{2 A} A R$ in addition to their respective cognate receptors (Figure $7 A$ ). Such off-target effects of monoamines on related monoamine receptors has been previously shown (Galinski et al., 2018). To confirm such direct activation of $D_{2}$ by noradrenaline and serotonin, we assessed the activation of $G \alpha_{i 2}$ and $G \alpha_{o B}$ and Barrestin2 recruitment in $D_{2}$ expressing cells in the presence of the $\mathrm{D}_{2}$-selective antagonist eticlopride. As expected, dopamine, noradrenaline and serotonin induced a concentration-dependent activation of $G \alpha_{\mathrm{i} 2}$ and $\mathrm{G} \alpha_{\mathrm{oB}}$, whereas only dopamine and noradrenaline promoted $\beta$ arrestin2 recruitment (Figure 7B, top panel). No or marginal activation was detected in parental cells not transfected with $D_{2}$ (Figure S3). In addition, cell pretreatment with the selective $D_{2}$ antagonist eticlopride completely blocked the $\mathrm{G}$ protein activation and Barrestin2 recruitment, strongly supporting a direct mode of activation of $D_{2}$ by the noradrenaline and serotonin ligands. Similarly, the noradrenaline- and dopamine-mediated activation of $G \alpha_{\mathrm{i} 2}$, $\mathrm{G} \alpha_{\mathrm{OB}}$ and $\beta$ arrestin2 observed in cells transfected with $\alpha_{2 \mathrm{~A}} \mathrm{AR}$ (Figure 7B, bottom panel) was completely blocked by the selective $\alpha_{2 A} A R$ antagonist WB4101.

One of the non-expected $G_{2} / G_{15}$ activation was observed in cells expressing either $C B_{1}$ or $C B_{2}$ following acetylcholine stimulation (Figure 7A). This could result either from (i) a "cis"-effect, where the tested receptor is directly activated by the ligands such as in the case of the monoaminergic ligand and receptors discussed above, or (ii) a "trans"-effect, where the tested receptor is indirectly activated following the activation of an endogenous receptor responding to the tested ligand. To test whether the $\mathrm{CB}_{1}$ receptor activation by acetylcholine is a trans-effect result from cross-talk, the activation was first confirmed using the $G \alpha_{o B}$ sensor. As for the $G_{2} / G_{15}$, acetylcholine led to an activation of $G_{\alpha B}$ in $C_{1}$-transfected cells. This activation as well as the activation by the CB agonist WIN55,212-2 were completely 
blocked by the CB inverse agonist, AM-630 (Figure 7C, left panel). However, the cholinergic antagonist atropine only blocked the response elicited by acetylcholine but not by WIN55,212-2 (Figure 7C, central panel). In addition, $G \alpha_{\text {ов }}$ activation by acetylcholine was not due to endogenous muscarinic receptors since no $\mathrm{G \alpha}_{\mathrm{OB}}$ response was observed in parental cells. Given that the $M_{3}$ muscarinic receptor, which is endogenously expressed at relatively high levels in HEK293 cells (Atwood et al., 2011), is strongly coupled to the $G_{q / 11}$ family, $C B_{1}$ expressing cells were pretreated with $\mathrm{G}_{\mathrm{q} / 11 / 14}$ inhibitor UBO-QIC prior to stimulation with acetylcholine. UBO-QIC pretreatment blocked $\mathrm{G}_{\mathrm{OB}}$ activation promoted by acetylcholine (Figure 7C, right panel) but not by WIN55,212-2 direct activation of $\mathrm{CB}_{1}$ (which does not couple to the $G_{q / 11}$; Figure $\mathbf{S 2}$ and Data $\mathbf{S 1}$ ). Altogether, these results demonstrate that $C_{1}$ activation by acetylcholine is indirect and involves the endogenous muscarinic acetylcholine receptors, potentially through a transactivation mechanism involving the production of an endogenous ligand. These data indicate that the $G_{2} / G_{15}$ combined sensor will be a useful tool to explore systems pharmacology and detect the interplay between receptors. 


\section{DISCUSSION}

This study describes the development and validation of a suite of genetically encoded ebBRET-based biosensors allowing live-cell mapping of GPCR/G protein coupling preferences covering 12 heterotrimeric G proteins. The novel EMTA biosensors were combined with previously described ebBRET-based ßarrestin trafficking sensors to provide a detailed description of the effector coupling landscape for 100 GPCR. The reported dataset reveals significant heterogeneity and diversity in GPCR-effector coupling, with certain receptors displaying extremely selective coupling preferences and others exhibiting great promiscuity in their effector engagement. Interestingly, certain receptors displayed differential coupling to $G$ proteins of the same family, revealing an underappreciated level of coupling selectivity. Finally, we show that $G_{z}$ and $G_{15}$ pathways are engaged by a vast majority of the receptors profiled. This observation led to the development of a novel quasi-universal combined $\mathrm{G}_{2} / \mathrm{G}_{15}$ biosensor applicable for safety screening and systems pharmacology.

Our EMTA biosensor platform offers several advantages relative to other available approaches. First, EMTA provides direct real-time measurement of proximal signaling events following GPCR activation (i.e., Ga protein activation and $\beta$ arrestin recruitment) and does not require amplification or extended incubation times for signal detection. This contrasts with methodologies classically used to assess GPCR signaling that largely rely on the detection of distal $2^{\text {nd }}$ messenger production (i.e., inositol phosphate (IP), $\mathrm{Ca}^{2+}, \mathrm{CAMP}$ ). Other assays relying on pathway-specific transcriptional activation of reporter genes (i.e., CRE, SRE, SRF-RE, NFAT-RE) (Cheng et al., 2010; Siehler, 2008) or engineered transcription- or proteolytically-activated reporter systems (i.e. PRESTO-TANGO (Kroeze et al., 2015) or TGF- $\alpha$ shedding assays (Inoue et al., 2019)) also involve amplification steps and long incubation times. Many of these relatively distal readouts rely on biological responses that can be modulated by multiple downstream signaling pathways and lead to cross-talk, complicating data interpretation (Mancini et al., 2015).

Second, our assays use native untagged GPCR and G protein subunits, contrary to complementation (i.e., split luciferase (Laschet et al., 2019), PRESTO-TANGO (Kroeze et al., 2015)), FRET/BRET-based G $\alpha-G \beta \gamma$ dissociation/receptor-G protein interaction (Bunemann et 
al., 2003; Gales et al., 2005; Gales et al., 2006; Hoffmann et al., 2005; Lohse et al., 2003; Mende et al., 2018; Namkung et al., 2018) or TGF- $\alpha$ shedding (Inoue et al., 2019) assays that require modification of receptors and/or G proteins. Modifying these core-signaling components could alter responses and complicate interpretation. The ability to work with unmodified receptors and $G$ proteins is illustrated by the detection of endogenous GPCR signaling in HEK293 (Figure S3) and makes EMTA amenable for use in native and (patho)physiologically relevant cells. In addition, all EMTA biosensors are based on a common assay principle and not a combination of distinct assay formats. This allows direct comparison between signaling outputs, minimizing artefacts due to different amplification or kinetic differences between the assays. The breadth and sensitivity of the platform not only allows detecting coupling selectivity between $\mathrm{G}$ protein families but also amongst members of the same family. The normalization method developed also allows quantitative comparison of coupling preferences across different receptors.

A potential caveat of EMTA is linked to the use of common effectors for the all members of a given $\mathrm{G}$ protein subtype family and not individual biosensors for each $\mathrm{G}$ protein subtype. It cannot be excluded that different members of a given subtype family may display different relative affinities for their common effector. However, such differences would be compensated by our data normalization (Figure $\mathbf{3 A}$ ).

Comparison of our dataset with those of Inoue et al. (Inoue et al., 2019) and GtoPdb (https://www.guidetopharmacology.org/) revealed commonalities but also highlights some notable differences. Globally, it was consistently noted that coupling to $G_{i / o}$ was proportionally predominant vs. coupling to other $G$ protein families, and all datasets displayed comparable $G$ protein coupling preferences $\left(G_{i / 0}>G_{q / 11}>G_{s} \geq G_{12 / 13}\right)$. Interestingly, all datasets reveal that $\mathrm{G}_{12 / 13}$-coupled receptors are consistently coupled to at least one other $\mathrm{G}$ protein subtype with a potency which is equivalent or better than the coupling to $\mathrm{G}_{12 / 13}$. Although the structural basis underlying this phenomenon remains unknown, the conclusion that $G_{12 / 13}$ is always activated in conjunction with other $G$ protein subtypes is bound to have biological consequences. Noticeably, functional interactions between $G_{q / 11}$ and $\mathrm{G}_{12 / 13}$ has been previously described (Namkung et al., 2018; Riobo and Manning, 2005). 
Both our study and GtoPdb identified only a limited fraction of receptors displaying extreme promiscuity in coupling to the 4 families ( $9 \%$ for our study; $1 \%$ for GtoPdb). This is in contrast to the data reported in Inoue et al. in which $26 \%$ of receptors were shown to engage all $4 \mathrm{G}$ protein families. Whether the higher apparent promiscuity reported in the latter study is linked to the use of chimeric $G$ proteins remains to be determined. The proportion of receptors displaying restricted coupling (i.e., to $1 \mathrm{G}$ protein family) is relatively similar between the datasets. Our analyses also revealed that the capacity of a given GPCR to couple to 1 or more $\mathrm{G}$ protein families is not linked to the nature of its ligand (Figure S2). A distinction between primary and secondary coupling based on the $\mathrm{pEC} \mathrm{C}_{50}$ has been proposed (Flock et al., 2017; Inoue et al., 2019) (https://www.guidetopharmacology.org/). In our study, higher potency toward one of the G protein subtype family engaged by a given receptor has also been generally observed although, in some cases, the $\mathrm{pEC}_{50}$ differences are modest (Table S1). Caution should, however, be exercised when considering this concept of primary coupling given that the measured $\mathrm{pEC}_{50}$ could be influenced by the expression levels of the different $\mathrm{G}$ proteins in a given cell.

A phenomenon revealed by our study is the differential coupling between members of the same $G$ protein family. This observation is particularly true for the $G_{i / o}$ family of $G$ proteins. This may not be surprising given that the $\mathrm{G}_{\mathrm{i} / \mathrm{o}}$ family has the largest number of members which are divided in 3 evolutionary sub-branches. Such intrafamily selectivity provides a new insight for understanding the evolutionary pressure that have contributed to the appearance and maintenance of 6 members of the $G_{i / o}$ family. Further work is needed to fully appreciate the functional consequences but detailed comparative analysis of the receptor vs. $\mathrm{G}_{\mathrm{i} / \mathrm{o}}$ subtype expression patterns in different tissues should shed some light on the physiological underpinning of this selectivity.

Another unique finding of our study relative to Inoue et al. (Inoue et al., 2019) is the large number of receptors coupled to $\mathrm{Ga}_{15}$ (Figure $6 \mathrm{C}$ ). Our observation is consistent with previous reports that demonstrate promiscuous $\mathrm{G \alpha}_{15}$ coupling and its uniqueness relative to other $\mathrm{G}$ proteins (Giannone et al., 2010). It is conceivable that the difference between the two studies relates to the use of full-length $G$ proteins in our assays and the requirement of additional structural elements in the $\mathrm{G}$ protein core, beyond the last 7 amino acids of $\mathrm{H} 5$, to 
stabilize $\mathrm{Ga}_{15}$ interaction with receptors. Our study also reveals a coupling divergence for $G \alpha_{15}$ relative to all other $G$ proteins of the $G_{q / 11}$ family (Figure $5 B$ ). $G \alpha_{15}$, which is in a distinct evolutionary branch than $\mathrm{Ga}_{\mathrm{q}}, \mathrm{G \alpha}_{11}$ and $\mathrm{G \alpha}_{14}$ also shows a number of differences with the other $\mathrm{G}_{\mathrm{q} / 11}$ family members. For instance, it is resistant to the action of $\mathrm{G}_{\mathrm{q} / 11}$ small molecule inhibitors (Schrage et al., 2015; Takasaki et al., 2004) and has a restricted expression pattern (hematopoietic and epithelial cells) (Giannone et al., 2010). Together, these observations indicate that $\mathrm{G \alpha}_{15}$ is clearly distinct from the other members of the $G_{q / 11}$ family with which it is usually classified.

Despite the overall congruence, the coupling profile differences between datasets highlight the importance of developing and using complementary approaches to draw common conclusions on GPCR functional selectivity. Whenever differences are noted, a better understanding of their sources (e.g., cell model, temperature, kinetics, $\mathrm{pH}$, tag insertion point, specific receptor isoform, receptor and $\mathrm{G}$ protein expression levels, etc.) should provide new insight on GPCR biology and pharmacology.

A limitation of any large-scale signaling study is that ligands may elicit responses downstream of receptors other than the one under study. We developed a $G_{z} / G_{15}$ quasiuniversal biosensor that enables efficient screening and detection of such polypharmacology and cross-talk systems pharmacology. The $G_{2} / G_{15}$ biosensor revealed the not so surprising action of monoamine ligands on closely related adrenergic, dopaminergic and serotonergic receptors (Figure 7). Maybe more importantly, it allowed to discover cross-talk between the $M_{3}$ and both $C B_{1}$ and $C B_{2}$ receptors, indicating that the stimulation of $M_{3}$ potentially promotes the release of a $C B_{1}$ and $C B_{2}$ agonist (Figure 7). The $G_{2} / G_{15}$ biosensor thus offers a great tool to further dissect the results from large-scale signaling studies and to explore systems pharmacology.

The EMTA platform, combined with the $G_{2} / G_{15}$ quasi-universal biosensor, offers many applications in the field of drug discovery and development. These tools are suited for high throughput screening of small molecules and biologics across an array of signaling pathways, allowing for the discovery of functionally selective molecules or for GPCR deorphanization campaigns. The ability of the EMTA platform to quantitatively assess both inter- and intra-G 
protein family selectivity expands the concept of functional selectivity and potential ligand bias beyond the dichotomic $G$ protein vs. Barrestin view. In addition, the $G_{2} / G_{15}$ quasiuniversal biosensor offers a rapid approach to characterize the polypharmacological action of ligands, a property that maybe particularly useful for the development of neuropsychiatric drugs (Dar et al., 2012; Roth et al., 2004). Similarly, this tool can be applied to assess the activity of various molecules on receptors linked to in vivo adverse reactions. Early profiling of compound activity on safety panels can i) rapidly help identify unsafe compounds destined for attrition, ii) help inform the design and selection of candidates most likely to emerge as marketed drugs and iii) be valuable in an antagonist mode to define off target activities.

Overall, this study advances our understanding and significantly improves the resolution of the known landscape of GPCR/G protein signaling selectivity, and presents novel tools allowing to further explore the biological and pharmacological impact of such selectivity profiles. Importantly, our work reveals a subtler level of selective effector coupling occurring within members of the same $G$ protein family, possibly explaining the evolutionary conservation of highly related $G$ proteins. Through our demonstration of ligand polypharmacology and cross-talk activation, we also exposed often overlooked and complex dimensions of GPCR activity. Globally, our observations lead to numerous questions related to the physiological, pathological and therapeutic importance of coupling diversity, especially in complex biological systems in which GPCR, ligand and effector expression levels vary across different cells and tissues. The tools and information provided by this study, coupled to other signaling profiling and omic-scale datasets, should help deconvolute the complexities of GPCR biology and pharmacology and lead to innovative therapeutic exploitation of GPCR. 


\section{ACKNOWLEDGMENTS}

We thank Shane C. Wright for scientific discussion and help with figures; Monique Lagacé for critical reading of the manuscript. The work was supported by a Foundation grant from CIHR (FDN-148431) to M.B. and grants from the Lundbeck Foundation (R313-2019-526) and Novo Nordisk Foundation (NNF17OC0031226) to D.E.G.; M.B. holds the Canada Research Chair in Signal Transduction and Molecular Pharmacology.

\section{AUTHOR CONTRIBUTIONS}

Conceptualization: C.A., A.M., B.B., C.L.G., S.S., X.L., D.E.G., M.B.;

Methodology: C.A., A.M., B.B., C.L.G., A.S.H., D.E.G., M.B.;

Investigation: C.A., A.M., B.B., C.N., H.K., F.G., M.H., V.L., S.M.;

Formal Analysis: C.A., A.M., A.S.H, D.E.G., M.B.;

Resources: A.M., E.F., J-P. F., S.S., X.L., M.B.;

Writing: C.A., A.M., and M.B. with feedback from all coauthors;

Funding Acquisition: S.S., D.E.G., M.B.;

Supervision: X.L. D.E.G., M.B.

\section{DECLARATION OF INTERESTS}

A.M., B.B., C.N., F.G. and S.M were employees of Domain Therapeutics North America during part or all of this research. E.F. is an employee and shareholder of Pfizer, Inc. J-P.F. is an employee of Pfizer Global R\&D and holds Pfizer stocks. S.S. and X.L. are employees and are part of the management of Domain Therapeutics. M.B. is the president of Domain Therapeutics scientific advisory board. B.B., C.L.G., H.K., M.H., V.L., M.B. have filed patent applications related to the biosensors used in this work and the technology has been licensed to Domain Therapeutics. C.A., A.S.H. and D.E.G have no competing interests to declare. 


\section{STAR METHODS \\ Resource Availability}

\section{Lead Contact}

Further information and requests for resources and reagents should be directed to and will be fulfilled by the Lead Contact, Michel Bouvier (michel.bouvier@umontreal.ca).

\section{Materials Availability}

Further information and requests for resources and reagents should be directed to and will be fulfilled upon reasonable request by the Lead Contact, Michel Bouvier (michel.bouvier@umontreal.ca).

The ebBRET sensors used in the study are protected by patent applications and have been licensed to Domain Therapeutics. Inquiries for potential commercial use should be addressed to: xleroy@domaintherapeutics.com. For non-commercial academic use, the sensors can be obtained freely under material transfer agreement upon request.

\section{Data and Code Availability}

Heatmaps in Figure $\mathbf{3}$ and pairwise comparisons in Figure $\mathbf{5}$ were generated using custom python scripts. Scripts are available from the co-corresponding author, David E. Gloriam (david.gloriam@sund.ku.dk) on request.

\section{Experimental Model and Subject Details}

\section{Cells}

HEK293 clonal cell line (HEK293SL cells), hereafter referred to as HEK293 cells, are described in previously published works (Luttrell et al., 2018; Namkung et al., 2018). HEK293 cells devoid of functional $G \alpha_{12}$ and $G \alpha_{13}\left(\Delta G_{12 / 13}\right)$ proteins were a gift from A. Inoue (Tohoku University, Sendai, Miyagi, Japan) and previously described (Devost et al., 2017; Luttrell et al., 2018; Namkung et al., 2016; Namkung et al., 2018). Cells were maintained in Dulbecco's Modified Eagle Medium (DMEM, Wisent) supplemented with $10 \%$ fetal bovine serum (FBS, Wisent) and $1 \%$ antibiotics (100 U/mL penicillin and $100 \mu \mathrm{g} / \mathrm{mL}$ streptomycin (PS); Wisent). Cells were grown at $37^{\circ} \mathrm{C}$ in $5 \% \mathrm{CO}_{2}$ and $90 \%$ humidity. 


\section{Method Details}

\section{Plasmids and ebBRET biosensor constructs}

Only human GPCR and human Ga subunits were used in this study. An open reading frame of each full-length GPCR was cloned into pcDNA3.1(+) expression plasmid. Except when otherwise specified, GPCR sequences were devoid of epitope tags.

$\mathrm{Ga}_{\mathrm{s}}$-67-Rlucll (Carr et al., 2014), ßarrestin1-Rlucll (Zimmerman et al., 2012), ßarrestin2-Rlucll (Quoyer et al., 2013), rGFP-CAAX (Namkung et al., 2016), EPAC (Leduc et al., 2009), PKNRBD-Rlucll (Namkung et al., 2018), HA- $\beta_{2} A R$ (Lavoie et al., 2002), signal peptide-Flag-AT 1 (Goupil et al., 2015) and EAAC-1 (Brabet et al., 1998) were previously described. Full-length, untagged $G \alpha$ subunits, $G \beta 1$ and $G \gamma 9$ were purchased from cDNA Resource Center. GRK2 was generously provided by Dr Antonio De Blasi (Istituto Neurologico Mediterraneo Neuromed, Pozzilli, Italy).

To selectively detect $\mathrm{G}_{\mathrm{i} / \mathrm{o}}$ activation, a construct coding for aa 1-142 of the effector Rap1 GTPase-activating protein (comprising a $\mathrm{G}_{\mathrm{i} / \mathrm{o}}$ binding domain) fused to Rluc8, was sequenceoptimized, synthetized and subcloned at TopGenetech. From this construct, a Rlucll tagged version of Rap1GAP (1-442) with a linker sequence (GSAGTGGRAIDIKLPAT) between Rap1GAP and Rlucll was created by Gibson assembly in pCDNA3.1_Hygro (+) GFP10-Rlucll, replacing GFP10. Three substitutions (i.e., S437A/S439A/S441A) were introduced into the Rap1GAP sequence by PCR-mediated mutagenesis. These putative (S437 and S439) and documented (S441) (McAvoy et al., 2009) protein kinase A phosphorylation sites were removed in order to eliminate any $\mathrm{G}_{\mathrm{s}}$-mediated Rap1GAP recruitment to the plasmamembrane.

To selectively detect $G_{q / 11}$ activation, a construct encoding the $G_{q}$ binding domain of the human p63 Rho guanine nucleotide exchange factor (p63RhoGEF; residues: 295-502) tagged with Rlucll was done from IMAGE clones (OpenBiosystems) and subcloned by Gibson assembly in pCDNA3.1_Hygro (+) GFP10-Rlucll, replacing GFP10. The $G_{q}$ binding domain of p63RhoGEF and Rlucll were separated by the peptidic linker ASGSAGTGGRAIDIKLPAT.

To selectively detect $\mathrm{G}_{12 / 13}$ activation, a construct encoding the $\mathrm{G}_{12 / 13}$ binding domain of the human PDZ-RhoGEF (residues: 281-483) tagged with Rlucll was done by PCR amplification from IMAGE clones (OpenBiosystems) and subcloned by Gibson assembly in 
pCDNA3.1_Hygro (+) GFP10-Rlucll, replacing GFP10. The peptidic linker GILREALKLPAT is present between Rlucll and the $\mathrm{G}_{12 / 13}$ binding domain of PDZ-RhoGEF.

\section{Transfection}

For BRET experiments, cells $\left(1.2 \mathrm{~mL}\right.$ at $3.5 \times 10^{5}$ cells per $\left.\mathrm{mL}\right)$ were transfected with a fixed final amount of pre-mixed biosensor-encoding DNA $(0.57 \mu \mathrm{g}$, adjusted with salmon sperm DNA; Invitrogen) and human receptor DNA. Transfections were performed using a polyethylenimine solution (PEI, $1 \mathrm{mg} / \mathrm{mL}$; Polysciences) diluted in $\mathrm{NaCl}$ (150 mM, pH 7.0; 3:1 PEI/DNA ratio). Gelatin solution (1\%; Sigma-Aldrich) was used to stabilize DNA/PEI transfection mixes. Following addition of cells to the stabilized DNA/PEI transfection mix, cells were immediately seeded $\left(3.5 \times 10^{4}\right.$ cells/well) into 96-well white microplates (Greiner Bio-one) and maintained in culture for the next $48 \mathrm{~h}$ in DMEM containing $2 \%$ FBS and $1 \%$ PS. DMEM medium without L-glutamine was used for transfection of cells with mGluR to avoid receptor activation and desensitization.

For $\mathrm{Ca}^{2+}$ experiments, cells $\left(3.5 \times 10^{4}\right.$ cells/well) were co-transfected with the indicated receptor, with or without $\mathrm{G \alpha}_{15}$ protein, using PEI and seeded in poly-ornithine coated 96well clear-bottomed black microplates (Greiner Bio-one) and maintained in culture for the next $48 \mathrm{~h}$.

For BRET-based imagery, cells ( $4 \times 10^{5}$ cells/dish) were seeded into $35-\mathrm{mm}$ poly-d-lysinecoated glass-bottom culture dishes (Mattek) in $2 \mathrm{ml}$ of fresh medium and incubated at $37^{\circ} \mathrm{C}$ in $5 \% \mathrm{CO}_{2}, 3$ day before imaging experiments. Twenty-four hours later, cells were transfected with EMTA ebBRET biosensors and the indicated receptor (i.e., p63-RhoGEFRlucll/rGFP-CAAX $+G \alpha_{q}$ and GnRHR, Rap1GAP-Rlucll/rGFP-CAAX $+G \alpha_{i 2}$ and $D_{2}$ or PDZRhoGEF-Rlucll/rGFP-CAAX $+\mathrm{G \alpha}_{13}$ and TP $\left.\alpha \mathrm{R}\right)$ using X-tremeGENE 9 DNA transfection reagent (3:1 reagent/DNA ratio; Roche) diluted in OptiMEM (Gibco, Cat\# 31985070) and maintained in culture for the next $48 \mathrm{~h}$ in DMEM containing $10 \% \mathrm{FBS}$ and $1 \% \mathrm{PS}$.

\section{Bioluminescence Resonance Energy Transfer Measurement}

Enhanced bystander BRET (ebBRET) was used to monitor the activation of each Ga protein, as well as Barrestin 1 and 2 recruitment to the plasma membrane (Namkung et al., 2016). $\mathrm{G} \alpha_{s}$ protein engagement was measured between the plasma membrane marker rGFP-CAAX and human $\mathrm{Ga}_{\mathrm{s}}$-Rlucll in presence of human $\mathrm{G} \beta 1, \mathrm{G} \gamma 9$ and the tested receptor. $G \alpha_{s}$ 
downstream cAMP production was determined using the EPAC biosensor (Leduc et al., 2009) and GPBA receptor. $G \alpha_{i / o}$ protein family activation was followed using the selective- $G_{i / o}$ effector Rap1GAP-Rlucll and rGFP-CAAX along with the human $G \alpha_{i 1}, G \alpha_{i 2}, G \alpha_{\circ A}, G \alpha_{o B}$ or $G \alpha_{z}$ subunits and the tested receptor. $G \alpha_{\mathrm{q} / 11}$ protein family activation was determined using the selective- $\mathrm{G}_{\mathrm{q} / 11}$ effector p63-RhoGEF-Rlucll and rGFP-CAAX along with the human $\mathrm{G}_{\mathrm{q}}$, $\mathrm{G \alpha}_{11}$, $\mathrm{G \alpha}_{14}$ or $\mathrm{G \alpha}_{15 / 16}$ subunit and the tested receptor. $\mathrm{G \alpha}_{12 / 13}$ protein family activation was monitored using the selective-G ${ }_{12 / 13}$ effector PDZ-RhoGEF-Rlucll and rGFP CAAX in presence of either $\mathrm{G \alpha}_{12}$ or $\mathrm{G \alpha}_{13}$ and the tested receptor. $\mathrm{G \alpha}_{12 / 13}$-downstream activation of the Rho pathway was measured using PKN-RBD-Rlucll and rGFP-CAAX with the indicated receptor. Barrestin recruitment to the plasma membrane was determined using DNA mix containing rGFP-CAAX and Barrestin1-Rlucll with GRK2 or Barrestin2-Rlucll alone or with GRK2 and the tested receptor. Glutamate transporters EAAC-1 and EAAT-1 were systematically cotransfected with the mGluR to prevent receptor activation and desensitization by glutamate secreted in the medium by the cells (Brabet et al., 1998). All ligands were also tested for potential activation of endogenous receptors by transfecting the biosensors without receptor DNA. The $\mathrm{G}_{2} / \mathrm{G}_{15}$ biosensor consists of a combination of the following plasmids: rGFP-CAAX, Rap1GAP-Rlucll, G $\alpha_{z}$, p63-RhoGEF-Rlucll and $G \alpha_{15}$.

The day of the BRET experiment, cells were incubated in HBSS for $1 \mathrm{~h}$ at room temperature (RT). Cells were then co-treated with increasing concentrations of ligand and the luciferase substrate coelenterazine prolume purple ( $1 \mu \mathrm{M}$, NanoLight Technologies) for $10 \mathrm{~min}$ at RT. Plates were read on a Synergy Neo microplate reader (BioTek Instruments, Inc.) equipped with $410 \pm 80 \mathrm{~nm}$ donor and $515 \pm 30 \mathrm{~nm}$ acceptor filters. The BRET signal $\left(\mathrm{BRET}^{2}\right)$ was determined by calculating the ratio of the light intensity emitted by the acceptor (515 $\mathrm{nm}$ ) over the light intensity emitted by the donor $(410 \mathrm{~nm})$. To validate the specificity of the biosensor responses, cells were pretreated in the absence or presence of either the $G \alpha_{q}$ inhibitor UBO-QIC (100 nM, $30 \mathrm{~min})$, the $\mathrm{G} \alpha_{\mathrm{i} / \mathrm{o}}$ inhibitor PTX (100 ng/ml, $18 \mathrm{~h}$ ) or the $\mathrm{G} \alpha_{\mathrm{s}}$ activator CTX (50 or $200 \mathrm{ng} / \mathrm{ml}, 4 \mathrm{~h}$ ) before stimulation with agonist. For ligand-cross receptor activation experiments, cells were pretreated for $10 \mathrm{~min}$ with increasing concentrations of antagonists or inverse agonist (eticlopride for $D_{2}$, WB4101 for $\alpha_{2 A} A R$, atropine for muscarinic receptors and $A M-630$ for $\mathrm{CB}_{1}$ ) before a 10 min stimulation with an $\mathrm{EC}_{80}$ concentration of the indicated agonist. BRET was measured as described above. For the safety target panel ligand screen using the combined $\mathrm{G}_{2} / \mathrm{G}_{15}$ sensor, basal ebBRET level was 
first measured 10 min following addition of coelenterazine prolume purple $(1 \mu \mathrm{M})$ and ebBRET level was measured again following a $10 \mathrm{~min}$ stimulation with a single dose of the indicated ligand ( $1 \mu \mathrm{M}$ for endothelin-1 and $10 \mu \mathrm{M}$ for all other ligands). Technical replicates for each receptor were included on the same 96-well plate. For kinetics experiment of $\mathrm{ET}_{\mathrm{A}}$ activation, basal BRET was measured during $150 \mathrm{sec}$ before cells stimulation with either vehicle (DMSO) or $1 \mu \mathrm{M}$ of endothelin-1 (at time $0 \mathrm{sec}$ ) and BRET signal was recorded each $30 \mathrm{sec}$ during $3570 \mathrm{sec}$. For the validation of $\mathrm{G}_{12 / 13}$-mediated signal by new identified $\mathrm{G}_{12 / 13^{-}}$ coupled receptor using RhoA activation sensor, cells were pretreated or not with the $G \alpha_{q}$ inhibitor YM-254890 (1 $\mathrm{\mu M}, 30 \mathrm{~min}$; Wako Pure Chemical Industries) before agonist stimulation for $10 \mathrm{~min}$.

\section{BRET Data analyses and coupling efficiency evaluation}

All BRET ratios were standardized using the equation below and represented as universal BRET (uBRET) values: $u$ BRET $=((B R E T$ ratio $-A) /(B-A)) * 10000$. Constants $A$ and $B$ correspond to the following values:

$A=$ pre-established BRET ratio obtained from transfection of negative control (vector coding for Rlucll alone);

$B=$ pre-established $B R E T$ ratio obtained from transfection of positive control (vector coding for a GFP10-Rlucll fusion protein).

For a given signaling pathway, uBRET values at each agonist concentration were normalized as the \% of the response obtained in the absence of agonist (vehicle) and concentrationresponse curves were fitted in GraphPad Prism 8 software using a four-parameter logistic nonlinear regression model. Results are expressed as mean \pm SEM of at least three independent experiments.

A ligand-promoted response was considered real when the $E_{\max }$ value was $\geq$ to the mean + $2 * S D$ of the response obtained in vehicle condition and that a $\mathrm{pEC}_{50}$ value could be determined in the agonist concentration range used to stimulate the receptor. Consequently, a score of 0 or 1 was assigned to each signaling pathway depending on an agonist's ability to activate the tested pathway ( $0=$ no activation; $1=$ activation). In the case were responses associated to endogenous receptor were detectable, we considered as 
"distorted" and exclude all the responses observed in the presence of transfected receptor for which $E_{\max }$ was $\leq$ to $2 *$ mean of the $E_{\max }$ value obtained with endogenous receptors or $\mathrm{pEC}_{50}$ was $\geq$ to $2 *$ mean of the $\mathrm{pEC}_{50}$ value obtained with endogenous receptors. Consequently, a score of 0 was assigned for these distorted responses in radial graph representation (Figure S2) and dose-response curves were placed on a gray background in signaling signature profile panels (Data S1). Whenever transfected receptors produced an increase in $E_{\max }$ or a left-shift in $\mathrm{pEC}_{50}$ values compared to endogenous receptors, responses were considered 'true' and were assigned with a score of 1 for radial graph representation (Figure S2) and dose-response curves were placed on a yellow background in signaling signature profile panels to indicate a partial contribution of endogenous receptors (Data S1).

We use a double normalization of $\mathrm{E}_{\max }$ and $\mathrm{pEC}_{50}$ values to compare the signaling efficiency obtained for the 100 GPCR across all receptors and pathways. $E_{\max }$ and $\mathrm{pEC} \mathrm{C}_{50}$ values deduced from concentration-response curves were first normalized between 0 and 1 across receptors as a function of a reference receptor yielding to the largest response for a given pathway. Then, these values were normalized between 0 and 1 for the same receptor across pathways, using the pathway with the largest response for this receptor as the reference. Given that ligand unit for the proton sensing receptors is different than other receptors (i.e., positive $\mathrm{pH}$ value for proton sensing receptors; Log of molarity for other receptors), it was not possible to calculate their double normalized $\mathrm{pEC}_{50}$ and compare them to the rest of tested receptors (Figure 3B).

For the safety target panel ligand screen using the combined $\mathrm{G}_{2} / \mathrm{G}_{15}$ sensor, the fold ligandinduced stimulation was calculated for each receptor by dividing the BRET ratio after ligand addition (measured at 10 minutes post stimulation) by the basal BRET ratio prior to receptor stimulation. Activation thresholds were defined as the mean $+2 * S D$ of the ligand-stimulated response obtained with receptor-null cells expressing only the combined $\mathrm{G}_{2} / \mathrm{G}_{15}$ sensor.

\section{$\mathrm{Ca}^{2+}$ mobilization assay}

The day of experiment, cells were incubated with $100 \mu \mathrm{L}$ of a $\mathrm{Ca}^{2+}$-sensitive dye-loading buffer (FLIPR calcium 5 assay kit, Molecular Devices) containing $2.5 \mathrm{mM}$ probenecid for $1 \mathrm{~h}$ at $37^{\circ} \mathrm{C}$ in a $5 \% \mathrm{CO}_{2}$ incubator. During a data run, cells in individual wells were exposed to an 
$\mathrm{EC}_{80}$ concentration of agonist, and fluorescent signals were recorded every $1.5 \mathrm{~s}$ for $3 \mathrm{~min}$ using the FlexStation II microplate reader (Molecular Devices). For receptors that also activate other $G_{q / 11}$ family members, cells were pretreated with the $G_{q / 11}$ inhibitor $Y M$ $254890\left(1 \mu \mathrm{M}, 30 \mathrm{~min}\right.$ ) before agonist stimulation. $\mathrm{G \alpha}_{15}$ is resistant to inhibition by $\mathrm{YM}$ 254890 , thus allowing to measure $\mathrm{Ca}^{2+}$ responses generated specifically by $\mathrm{G \alpha}_{15}$.

\section{BRET-based imaging}

BRET images were obtained as previously described (Kobayashi et al., 2019). Briefly, the day of imaging experiment, cells were carefully rinsed with HBSS, and images were acquired before and after agonists addition (100 nM for $\mathrm{GnRH}$ and U46619, and $1 \mu \mathrm{M}$ for dopamine) diluted in HBSS in presence of the luciferase substrate coelenterazine prolume purple (20 $\mu \mathrm{M}$, NanoLight Technologies).

Images were recorded using an inverted microscope (Nikon Eclipse Ti-U) equipped with x60 objective lens (Nikon CFI Apochromat TIRF) and EM-CCD camera (Nuvu HNu 512). Measurements were carried out in photon counting mode with EM gain 3,000. Exposure time of each photon counting was 100 ms. Successive 100 frames were acquired alternatively with $480 \mathrm{~nm}$ longpass filter (acceptor frames) or without filter (total luminescence frames), and integrated. Image integrations were repeated 5 times and 500 frames of acceptor and total luminescence were used to generate each image.

BRET values were obtained by dividing acceptor counts by total luminescence counts pixelwise. BRET values from 0.0 to 0.5 were allocated to 'jet' heatmap array using MATLAB 2019b. Brightness of each pixel was mapped from the signal level of total luminescence image. $0 \%$ and $99.9 \%$ signal strength were allocated to the lowest and highest brightness to exclude the influence of defective pixels with gamma correction factor of 2.0.

The movie was generated using ImageJ 1.52a. Frame rate is 3 frames/sec, and frame interval is $100 \mathrm{sec}$. The field of view of the movie is $137 \mathrm{um} \times 137 \mathrm{um}$.

\section{Comparison of data from the EMTA ebBRET assay with known couplings}

The set of 394 annotated human non-olfactory GPCR and their annotated primary and secondary transducers was obtained from the International Union of Basic and Clinical Pharmacology/British Pharmacological Society (IUPHAR/BPS) Guide to Pharmacology database's Rest API (Armstrong et al., 2020). Secondary and primary transduction 
annotations were obtained for 251 GPCR and aggregated into a single coupling descriptor, i.e. coupling and non-coupling. Coupling profiles for 147 GPCR have been obtained from Inoue et al. (Inoue et al., 2019), where coupling was assigned for logRAi values $\geq-1$. On the family level, coupling has been assigned if at least one member is described as coupling.

\section{Clustering and pairwise distance calculations}

Clustering of double normalised coupling profiles (see BRET Data analyses and coupling efficiency evaluation), was performed using clustermap. Pairwise distances between observations in all 15 pathways have been calculated using the 'correlation' distance matrix in the pdist function from scipy. The Pearson correlation coefficient $p$-value was mapped to show statistically significant pairwise correlations as indicated in cells by ${ }^{*} p \leq 0.05 ; * * p \leq$ $0.005 ; * * p \leq 0.0005$.

Similarly, Euclidean pairwise distances have been calculated between $\mathrm{G}$ proteins to compare $\mathrm{G}$ protein sequence similarities with the receptor distance matrix of coupling profiles, i.e. the vectors containing double normalized $E_{\max }$ values for all receptors for that pathway. $G$ protein sequences were collected through the GPCRdb API (http://gpcrdb.org/services/reference/) (Pandy-Szekeres et al., 2018) using Python scripts. Pairwise sequence identities have been calculated for the full-length sequence, the Helix 5 domain, the Helix 5 domains last 7 amino acids as used by Inoue et al. (Inoue et al., 2019) as $\mathrm{G}$ protein chimeras, and the $\mathrm{G}$ protein barcode described in Flock et al. (Flock et al., 2017).

\section{Statistical Analyses}

Curve fitting and statistical analyses were performed using GraphPad Prism 8.3 software and methods are described in the legends of the figures. Significance was determined as $p<$ 0.05 . 


\section{REFERENCES}

Armstrong, J.F., Faccenda, E., Harding, S.D., Pawson, A.J., Southan, C., Sharman, J.L., Campo, B., Cavanagh, D.R., Alexander, S.P.H., Davenport, A.P., et al. (2020). The IUPHAR/BPS Guide to PHARMACOLOGY in 2020: extending immunopharmacology content and introducing the IUPHAR/MMV Guide to MALARIA PHARMACOLOGY. Nucleic Acids Res 48, D1006-D1021.

Atwood, B.K., Lopez, J., Wager-Miller, J., Mackie, K., and Straiker, A. (2011). Expression of G protein-coupled receptors and related proteins in HEK293, AtT20, BV2, and N18 cell lines as revealed by microarray analysis. BMC Genomics 12, 14.

Azzi, M., Charest, P.G., Angers, S., Rousseau, G., Kohout, T., Bouvier, M., and Pineyro, G. (2003). Beta-arrestin-mediated activation of MAPK by inverse agonists reveals distinct active conformations for $G$ protein-coupled receptors. Proc Natl Acad Sci U S A 100, 11406-11411.

Barak, L.S., Salahpour, A., Zhang, X., Masri, B., Sotnikova, T.D., Ramsey, A.J., Violin, J.D., Lefkowitz, R.J., Caron, M.G., and Gainetdinov, R.R. (2008). Pharmacological characterization of membrane-expressed human trace amineassociated receptor 1 (TAAR1) by a bioluminescence resonance energy transfer cAMP biosensor. Mol Pharmacol 74, 585-594.

Bowes, J., Brown, A.J., Hamon, J., Jarolimek, W., Sridhar, A., Waldron, G., and Whitebread, S. (2012). Reducing safety-related drug attrition: the use of in vitro pharmacological profiling. Nat Rev Drug Discov 11, 909-922.

Brabet, I., Parmentier, M.L., De Colle, C., Bockaert, J., Acher, F., and Pin, J.P. (1998). Comparative effect of L-CCG-I, DCG-IV and gamma-carboxy-L-glutamate on all cloned metabotropic glutamate receptor subtypes. Neuropharmacology 37, 1043-1051.

Carr, R., 3rd, Du, Y., Quoyer, J., Panettieri, R.A., Jr., Janz, J.M., Bouvier, M., Kobilka, B.K., and Benovic, J.L. (2014). Development and characterization of pepducins as Gs-biased allosteric agonists. J Biol Chem 289, 35668-35684.

Casey, P.J., Fong, H.K., Simon, M.I., and Gilman, A.G. (1990). Gz, a guanine nucleotide-binding protein with unique biochemical properties. J Biol Chem 265, 2383-2390. 
Cheng, Z., Garvin, D., Paguio, A., Stecha, P., Wood, K., and Fan, F. (2010). Luciferase Reporter Assay System for Deciphering GPCR Pathways. Curr Chem Genomics 4, 84-91.

Dar, A.C., Das, T.K., Shokat, K.M., and Cagan, R.L. (2012). Chemical genetic discovery of targets and anti-targets for cancer polypharmacology. Nature 486, 8084.

De Haan, L., and Hirst, T.R. (2004). Cholera toxin: a paradigm for multi-functional engagement of cellular mechanisms (Review). Mol Membr Biol 21, 77-92.

Devost, D., Sleno, R., Petrin, D., Zhang, A., Shinjo, Y., Okde, R., Aoki, J., Inoue, A., and Hebert, T.E. (2017). Conformational Profiling of the AT1 Angiotensin II Receptor Reflects Biased Agonism, G Protein Coupling, and Cellular Context. J Biol Chem 292, 5443-5456.

Ehrlich, A.T., Semache, M., Gross, F., Da Fonte, D.F., Runtz, L., Colley, C., Mezni, A., Le Gouill, C., Lukasheva, V., Hogue, M., et al. (2019). Biased Signaling of the Mu Opioid Receptor Revealed in Native Neurons. iScience 14, 47-57.

Flock, T., Hauser, A.S., Lund, N., Gloriam, D.E., Balaji, S., and Babu, M.M. (2017). Selectivity determinants of GPCR-G-protein binding. Nature 545, 317-322.

Fukuhara, S., Chikumi, H., and Gutkind, J.S. (2001). RGS-containing RhoGEFs: the missing link between transforming G proteins and Rho? Oncogene 20, 1661-1668.

Galandrin, S., Oligny-Longpre, G., and Bouvier, M. (2007). The evasive nature of drug efficacy: implications for drug discovery. Trends Pharmacol Sci 28, 423-430.

Galinski, S., Wichert, S.P., Rossner, M.J., and Wehr, M.C. (2018). Multiplexed profiling of GPCR activities by combining split TEV assays and EXT-based barcoded readouts. Sci Rep 8, 8137.

Giannone, F., Malpeli, G., Lisi, V., Grasso, S., Shukla, P., Ramarli, D., Sartoris, S., Monsurro, V., Krampera, M., Amato, E., et al. (2010). The puzzling uniqueness of the heterotrimeric G15 protein and its potential beyond hematopoiesis. J Mol Endocrinol 44, 259-269.

Goupil, E., Fillion, D., Clement, S., Luo, X., Devost, D., Sleno, R., Petrin, D., Saragovi, H.U., Thorin, E., Laporte, S.A., et al. (2015). Angiotensin II type I and prostaglandin F2alpha receptors cooperatively modulate signaling in vascular smooth muscle cells. J Biol Chem 290, 3137-3148. 
Hauser, A.S., Attwood, M.M., Rask-Andersen, M., Schioth, H.B., and Gloriam, D.E. (2017). Trends in GPCR drug discovery: new agents, targets and indications. Nat Rev Drug Discov 16, 829-842.

Hauser, A.S., Gloriam, D.E., Brauner-Osborne, H., and Foster, S.R. (2020). Novel approaches leading towards peptide GPCR de-orphanisation. Br J Pharmacol 177, 961-968.

Inoue, A., Raimondi, F., Kadji, F.M.N., Singh, G., Kishi, T., Uwamizu, A., Ono, Y., Shinjo, Y., Ishida, S., Arang, N., et al. (2019). Illuminating G-Protein-Coupling Selectivity of GPCRs. Cell 177, 1933-1947 e1925.

Jordan, J.D., Carey, K.D., Stork, P.J., and lyengar, R. (1999). Modulation of rap activity by direct interaction of Galpha(o) with Rap1 GTPase-activating protein. J Biol Chem 274, 21507-21510.

Kawamata, Y., Fujii, R., Hosoya, M., Harada, M., Yoshida, H., Miwa, M., Fukusumi, S., Habata, Y., Itoh, T., Shintani, Y., et al. (2003). A G protein-coupled receptor responsive to bile acids. J Biol Chem 278, 9435-9440.

Kenakin, T. (2019). Biased Receptor Signaling in Drug Discovery. Pharmacol Rev 71, 267-315.

Kobayashi, H., Picard, L.P., Schonegge, A.M., and Bouvier, M. (2019). Bioluminescence resonance energy transfer-based imaging of protein-protein interactions in living cells. Nat Protoc 14, 1084-1107.

Kroeze, W.K., Sassano, M.F., Huang, X.P., Lansu, K., McCorvy, J.D., Giguere, P.M., Sciaky, N., and Roth, B.L. (2015). PRESTO-Tango as an open-source resource for interrogation of the druggable human GPCRome. Nat Struct Mol Biol 22, 362369.

Laschet, C., Dupuis, N., and Hanson, J. (2019). A dynamic and screening-compatible nanoluciferase-based complementation assay enables profiling of individual GPCR-G protein interactions. J Biol Chem 294, 4079-4090.

Lavoie, C., Mercier, J.F., Salahpour, A., Umapathy, D., Breit, A., Villeneuve, L.R., Zhu, W.Z., Xiao, R.P., Lakatta, E.G., Bouvier, M., et al. (2002). Beta 1/beta 2adrenergic receptor heterodimerization regulates beta 2-adrenergic receptor internalization and ERK signaling efficacy. J Biol Chem 277, 35402-35410.

Leduc, M., Breton, B., Gales, C., Le Gouill, C., Bouvier, M., Chemtob, S., and Heveker, N. (2009). Functional selectivity of natural and synthetic prostaglandin EP4 receptor ligands. J Pharmacol Exp Ther 331, 297-307. 
Luttrell, L.M., Wang, J., Plouffe, B., Smith, J.S., Yamani, L., Kaur, S., Jean-Charles, P.Y., Gauthier, C., Lee, M.H., Pani, B., et al. (2018). Manifold roles of betaarrestins in GPCR signaling elucidated with siRNA and CRISPR/Cas9. Sci Signal 11.

Lutz, S., Shankaranarayanan, A., Coco, C., Ridilla, M., Nance, M.R., Vettel, C., Baltus, D., Evelyn, C.R., Neubig, R.R., Wieland, T., et al. (2007). Structure of Galphaq-p63RhoGEF-RhoA complex reveals a pathway for the activation of RhoA by GPCRs. Science 318, 1923-1927.

Mancini, A., Frauli, M., and Breton, B. (2015). Exploring the Technology Landscape of 7TMR Drug Signaling Profiling. Curr Top Med Chem 15, 2528-2542.

McAvoy, T., Zhou, M.M., Greengard, P., and Nairn, A.C. (2009). Phosphorylation of Rap1GAP, a striatally enriched protein, by protein kinase A controls Rap1 activity and dendritic spine morphology. Proc Natl Acad Sci U S A 106, 3531-3536.

Meng, J., and Casey, P.J. (2002). Activation of Gz attenuates Rap1-mediated differentiation of PC12 cells. J Biol Chem 277, 43417-43424.

Meng, J., Glick, J.L., Polakis, P., and Casey, P.J. (1999). Functional interaction between Galpha(z) and Rap1GAP suggests a novel form of cellular cross-talk. J Biol Chem 274, 36663-36669.

Milligan, G., and Kostenis, E. (2006). Heterotrimeric G-proteins: a short history. Br J Pharmacol 147 Suppl 1, S46-55.

Namkung, Y., Le Gouill, C., Lukashova, V., Kobayashi, H., Hogue, M., Khoury, E., Song, M., Bouvier, M., and Laporte, S.A. (2016). Monitoring G protein-coupled receptor and beta-arrestin trafficking in live cells using enhanced bystander BRET. Nat Commun 7, 12178.

Namkung, Y., LeGouill, C., Kumar, S., Cao, Y., Teixeira, L.B., Lukasheva, V., Giubilaro, J., Simoes, S.C., Longpre, J.M., Devost, D., et al. (2018). Functional selectivity profiling of the angiotensin II type 1 receptor using pathway-wide BRET signaling sensors. Sci Signal 11.

Oldham, W.M., and Hamm, H.E. (2008). Heterotrimeric G protein activation by Gprotein-coupled receptors. Nat Rev Mol Cell Biol 9, 60-71.

Pandy-Szekeres, G., Munk, C., Tsonkov, T.M., Mordalski, S., Harpsoe, K., Hauser, A.S., Bojarski, A.J., and Gloriam, D.E. (2018). GPCRdb in 2018: adding GPCR structure models and ligands. Nucleic Acids Res 46, D440-D446. 
Quoyer, J., Janz, J.M., Luo, J., Ren, Y., Armando, S., Lukashova, V., Benovic, J.L., Carlson, K.E., Hunt, S.W., 3rd, and Bouvier, M. (2013). Pepducin targeting the C$\mathrm{X}-\mathrm{C}$ chemokine receptor type 4 acts as a biased agonist favoring activation of the inhibitory G protein. Proc Natl Acad Sci U S A 110, E5088-5097.

Riobo, N.A., and Manning, D.R. (2005). Receptors coupled to heterotrimeric G proteins of the G12 family. Trends Pharmacol Sci 26, 146-154.

Rojas, R.J., Yohe, M.E., Gershburg, S., Kawano, T., Kozasa, T., and Sondek, J. (2007). Galphaq directly activates p63RhoGEF and Trio via a conserved extension of the Dbl homology-associated pleckstrin homology domain. J Biol Chem 282, 29201-29210.

Roth, B.L., Sheffler, D.J., and Kroeze, W.K. (2004). Magic shotguns versus magic bullets: selectively non-selective drugs for mood disorders and schizophrenia. Nat Rev Drug Discov 3, 353-359.

Schrage, R., Schmitz, A.L., Gaffal, E., Annala, S., Kehraus, S., Wenzel, D., Bullesbach, K.M., Bald, T., Inoue, A., Shinjo, Y., et al. (2015). The experimental power of FR900359 to study Gq-regulated biological processes. Nat Commun 6, 10156.

Siehler, S. (2008). Cell-based assays in GPCR drug discovery. Biotechnol J 3, 471483.

Smith, J.S., Lefkowitz, R.J., and Rajagopal, S. (2018). Biased signalling: from simple switches to allosteric microprocessors. Nat Rev Drug Discov 17, 243-260.

Sriram, K., and Insel, P.A. (2018). G Protein-Coupled Receptors as Targets for Approved Drugs: How Many Targets and How Many Drugs? Mol Pharmacol 93, 251-258.

Stallaert, W., Christopoulos, A., and Bouvier, M. (2011). Ligand functional selectivity and quantitative pharmacology at $\mathrm{G}$ protein-coupled receptors. Expert Opin Drug Discov 6, 811-825.

Takasaki, J., Saito, T., Taniguchi, M., Kawasaki, T., Moritani, Y., Hayashi, K., and Kobori, M. (2004). A novel Galphaq/11-selective inhibitor. J Biol Chem 279, 47438-47445.

Tanabe, S., Kreutz, B., Suzuki, N., and Kozasa, T. (2004). Regulation of RGSRhoGEFs by Galpha12 and Galpha13 proteins. Methods Enzymol 390, 285-294.

Wedegaertner, P.B., Bourne, H.R., and von Zastrow, M. (1996). Activation-induced subcellular redistribution of Gs alpha. Mol Biol Cell 7, 1225-1233. 
Wettschureck, N., and Offermanns, S. (2005). Mammalian G proteins and their cell type specific functions. Physiol Rev 85, 1159-1204.

Zimmerman, B., Beautrait, A., Aguila, B., Charles, R., Escher, E., Claing, A., Bouvier, M., and Laporte, S.A. (2012). Differential beta-arrestin-dependent conformational signaling and cellular responses revealed by angiotensin analogs. Sci Signal 5, ra33. 


\section{FIGURES}

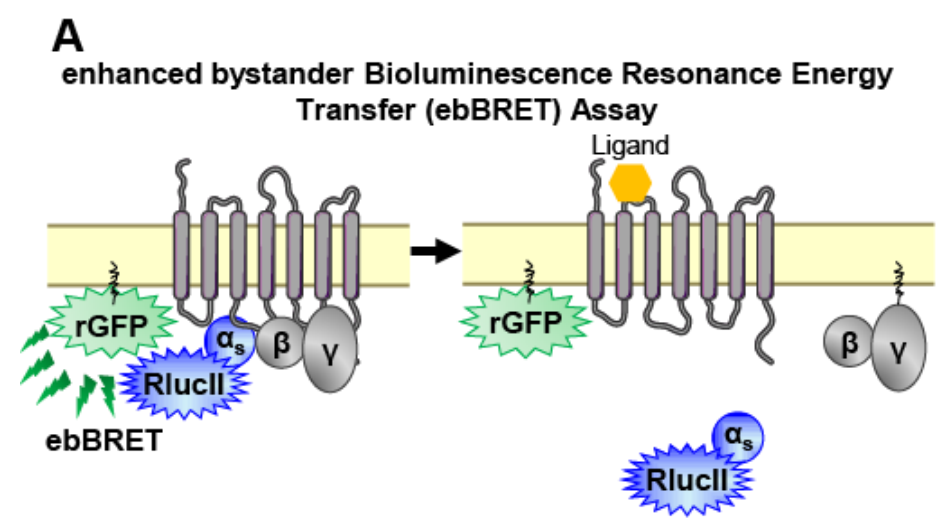

B

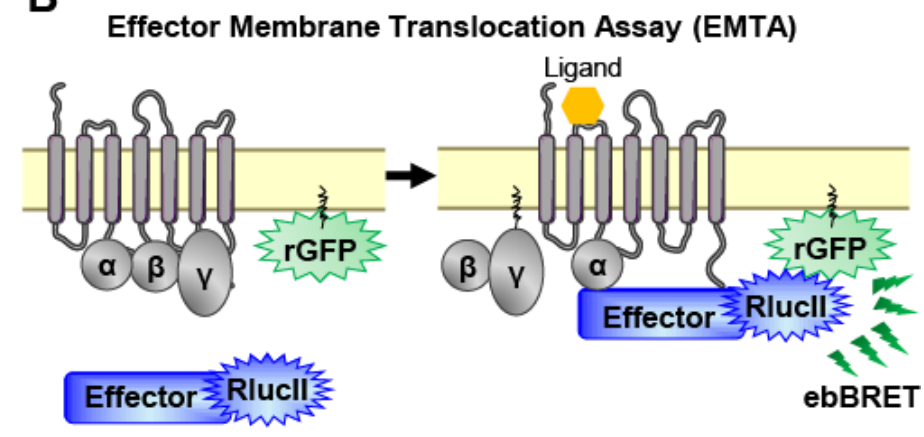

C

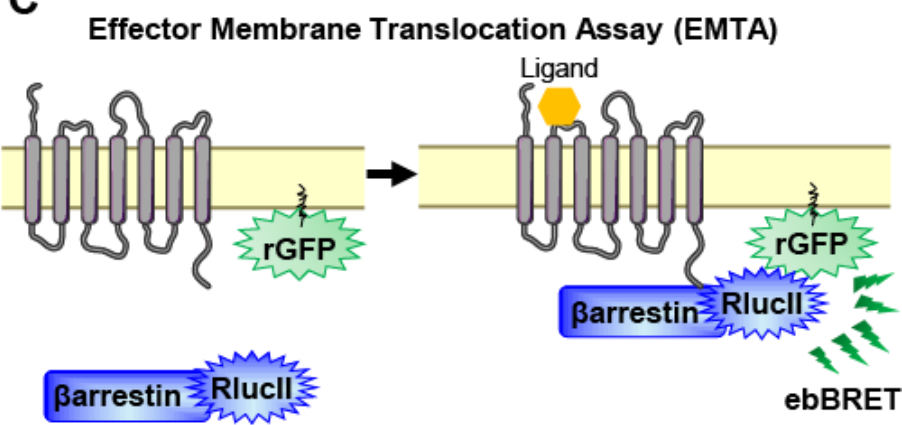

Figure 1. EMTA ebBRET platform to monitor $G$ proteins activation and Barrestins recruitment.

(A) Schematic of the ebBRET sensor for monitoring $G \alpha_{s}$ activation. Internalization of activated Rlucll-tagged $G \alpha_{s}\left(G \alpha_{s}-R l u c l l\right)$ following receptor stimulation decreases ebBRET with the membrane-anchored rGFP-CAAX.

(B) Illustration of the Effector Membrane Translocation Assay (EMTA) to monitor Ga protein activation. Upon receptor activation, Rlucll-tagged effector proteins (Effector-Rlucll) translocate towards and interact with active $G \alpha$ subunits from each $G$ protein family, leading to increased ebBRET.

(C) Principle of the ebBRET-based assay monitoring Barrestins recruitment to the plasma membrane. Upon receptor activation, Rlucll-tagged ßarrestins (ßarrestin-Rlucll) translocate to the plasma membrane, thus increasing ebBRET with rGFP-CAAX. 
A

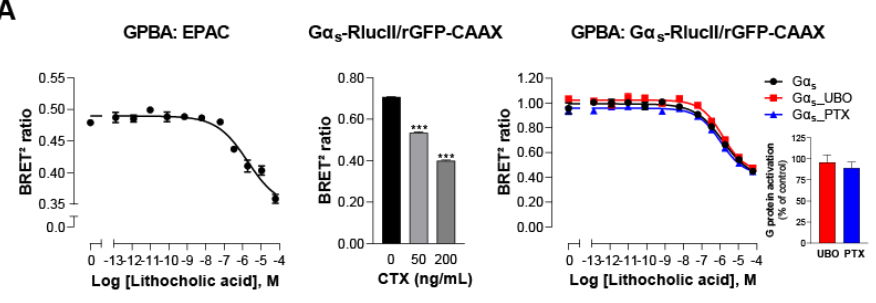

B

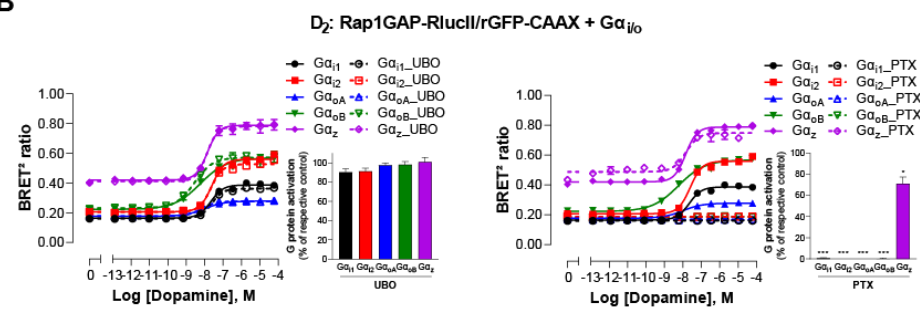

C

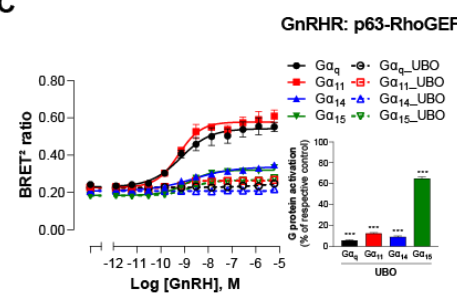

$\log [\mathrm{GnRH}], \mathrm{M}$

D

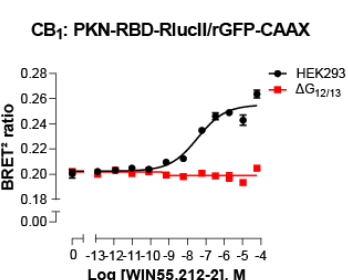

CB: PDZ-RhoGEF-Rlucll/rGFP-CAAX + Ga 121
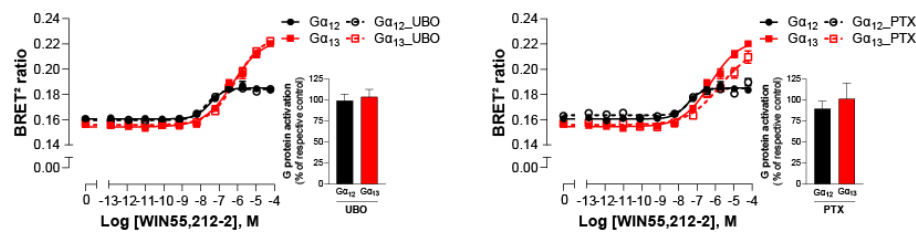

Figure 2. Validation of EMTA ebBRET-based sensors to monitor $G \alpha$ protein activation.

(A) Pharmacological validation of the $\mathrm{Ga}_{\mathrm{s}}$ activation sensor. HEK293 cells were transfected with the GPBA receptor and the EPAC (left panel) or the $G \alpha_{s}$ activation (central and right panels) sensors. Left panel: Dose response curve using the EPAC sensor. Central panel: Activation of the $G \alpha_{s}$ sensor using CTX, a $\mathrm{Ga}_{\mathrm{s}}$ activator. Right panel: Dose response curves using the $G \alpha_{\text {s }}$ activation sensor in the presence or absence of UBO-QIC or PTX, inhibitors of $G \alpha_{q}$ or $G \alpha_{i / 0}$, respectively. Inset; $E_{\max }$ values determined from dose-response curves of inhibitors-pretreated cells. (B) Pharmacological validation of the $G \alpha_{i / o}$ activation sensor. HEK293 cells were transfected with the $D_{2}$ receptor and the $G \alpha_{i / o}$ familyspecific sensor, along with each $G \alpha_{i / o}$ subunit. Dose response curve using the $G \alpha_{i / o}$ activation sensor, in the presence or absence of UBO-QIC (left panel) or PTX (right panel) inhibitors. Insets; $E_{\max }$ values determined from dose-response curves of inhibitors-pretreated cells.

(C) Pharmacological validation of the $G \alpha_{q / 11}$ activation sensor. HEK293 cells were transfected with the $\mathrm{GnRH}$ receptor and the $G \alpha_{q / 11}$ family-specific sensors, along with each $G \alpha_{q / 11}$ subunit. Dose response curve using $\mathrm{G}_{\mathrm{q} / 11}$ activation sensor, in the presence or absence of UBO-QIC (left panel) or PTX (right panel) inhibitors. Insets; $\mathrm{E}_{\max }$ values determined from dose-response curves of inhibitors-pretreated cells.

(D) Validation of the $\mathrm{G \alpha}_{12 / 13}$ activation sensor. Cells were transfected with the $\mathrm{CB}_{1}$ receptor and one of the $G \alpha_{12 / 13}$ activation sensors, along with the $G \alpha_{12}$ or $G \alpha_{13}$ subunits. Dose response curve of the parental and devoid of $\mathrm{G}_{12 / 13}\left(\Delta \mathrm{G}_{12 / 13}\right)$ HEK293 cells (top panel) or HEK293 cells (bottom panel) using the PKN-RBD-Rlucll/rGFP-CAAX (top panel) or PDZRhoGEF-Rlucll/rGFP-CAAX sensors (top right and bottom panels), pretreated or not with UBO-QIC or PTX (bottom panels).

Data are expressed as BRET ratio for the dose response curves or expressed in \% of respective control cells ( $E_{\max }$ graphs) and are means \pm SEM of $3(A-C)$ or $4(D)$ independent experiments. One Way ANOVA test (A) or Unpaired t test (B-D): ${ }^{*} p<0.05$ and ${ }^{* * *} p<0.001$ compared to control cells. 


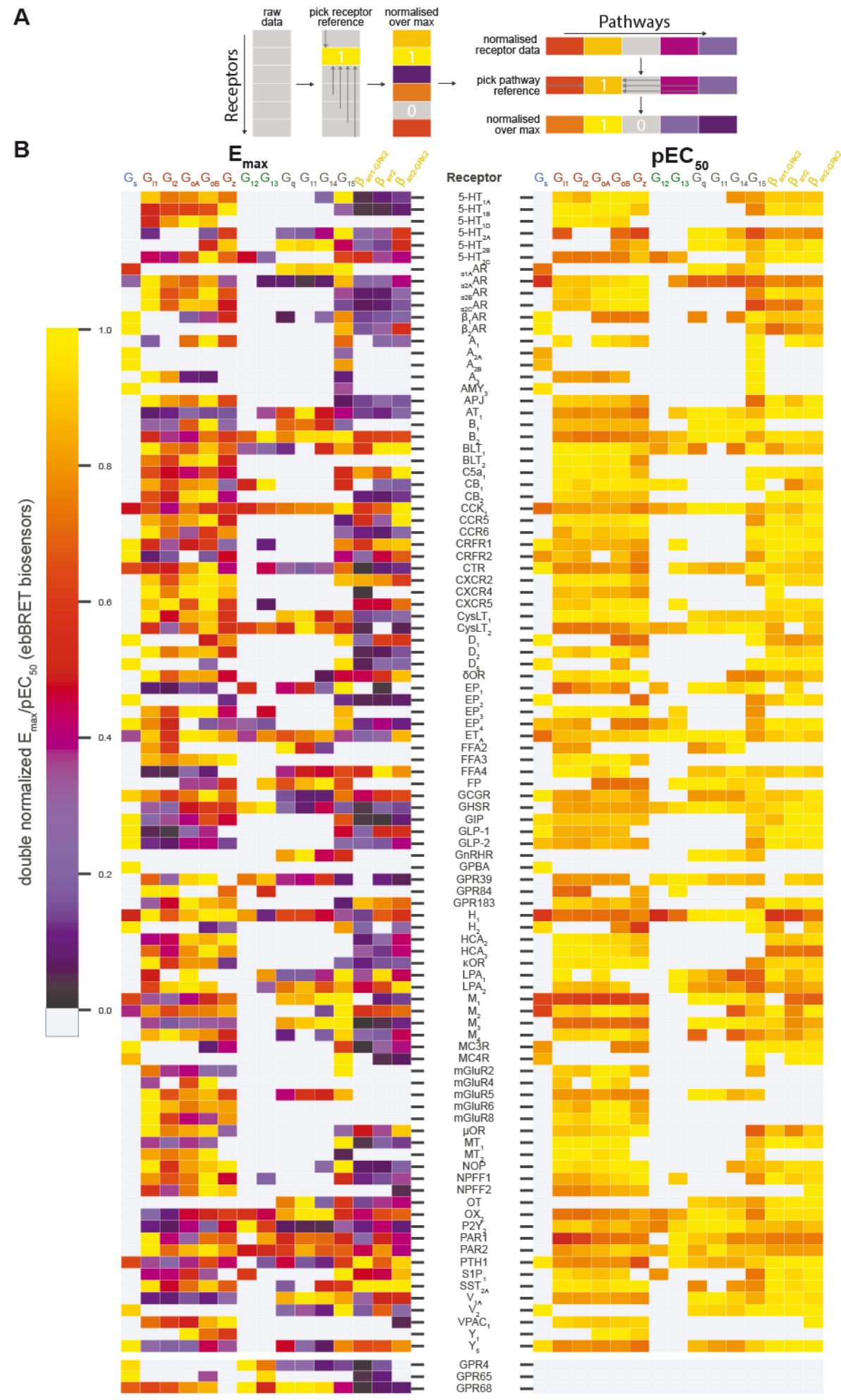

Figure 3. Heatmaps illustrating the diversity of receptor-specific signaling signatures detected with the EMTA ebBRET platform.

(A) First, values within each pathway were normalized relative to the maximal response observed across all receptors (max. $=1$; left panel). These values were then normalized across pathways for the same receptor, with the highest-ranking pathway serving as the reference $(=1$; right panel).

(B) Heatmap representation of double normalized $\mathrm{E}_{\max }$ (left) and $\mathrm{pEC}_{50}$ (right) data. Empty cells (grey) indicate no coupling. 
A

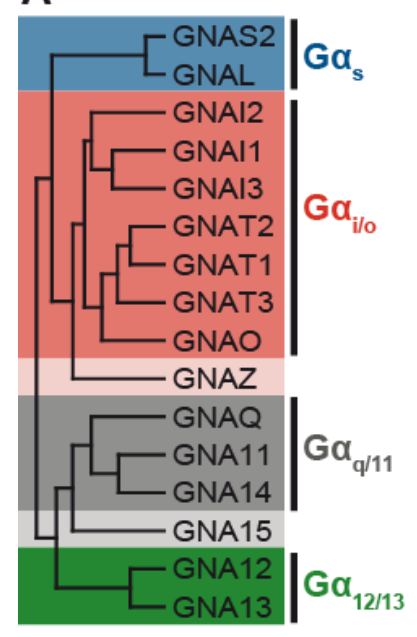

B

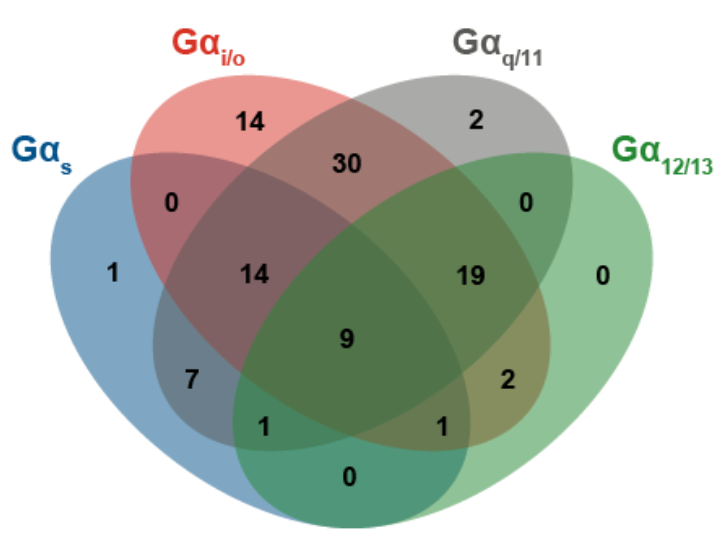

E

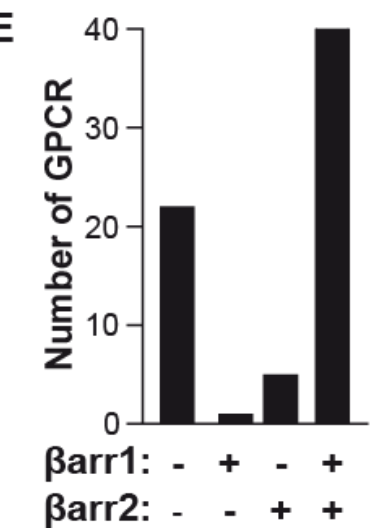

Figure 4. The EMTA ebBRET platform reveals the large diversity of coupling selectivity between $\mathrm{G}$ protein families.

(A) Sequence-relationships between $G \alpha$ proteins and classification into $G$ protein families.

(B) Venn diagram showing the numbers of receptors coupled to each $G$ protein family in the EMTA ebBRET biosensor assay.

(C) Evaluation of receptors coupling promiscuity: number of receptors that couple to members of $1,2,3$ or $4 \mathrm{G}$ protein families.

(D) Determination of $G$ protein subunits coupling frequency: number of receptors that activate each $\mathrm{G} \alpha$ subunit.

(E) Proportion of receptors recruiting ßarrestins: number of receptors that do not recruit (-/) or that recruit either (+/- or $-/+$ ) or both (+/+) ßarrestin isotypes.

All data are based on double normalized $E_{\max }$ values from Figure 3 . 
A

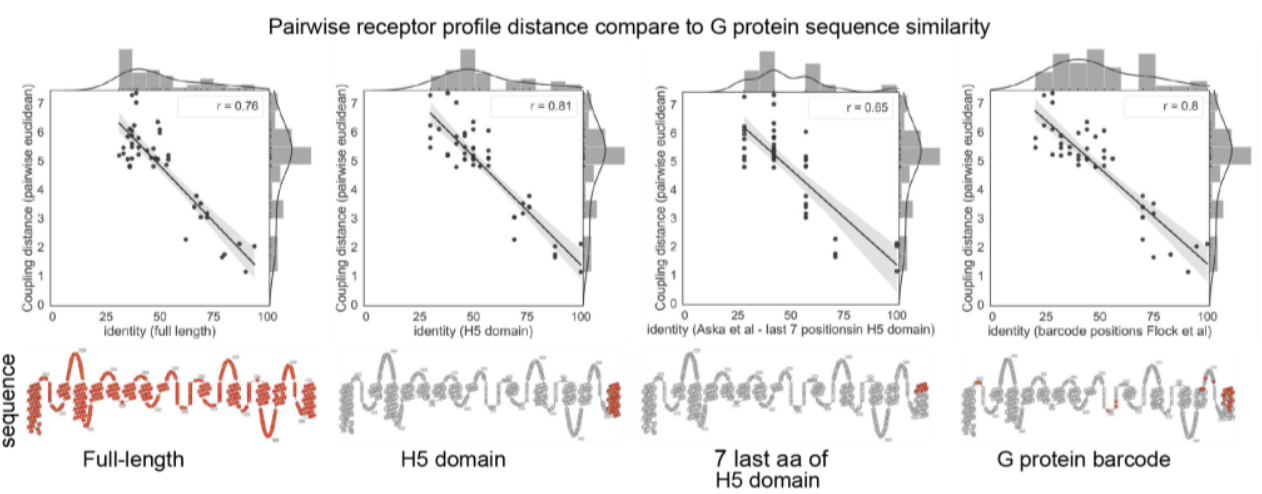

B

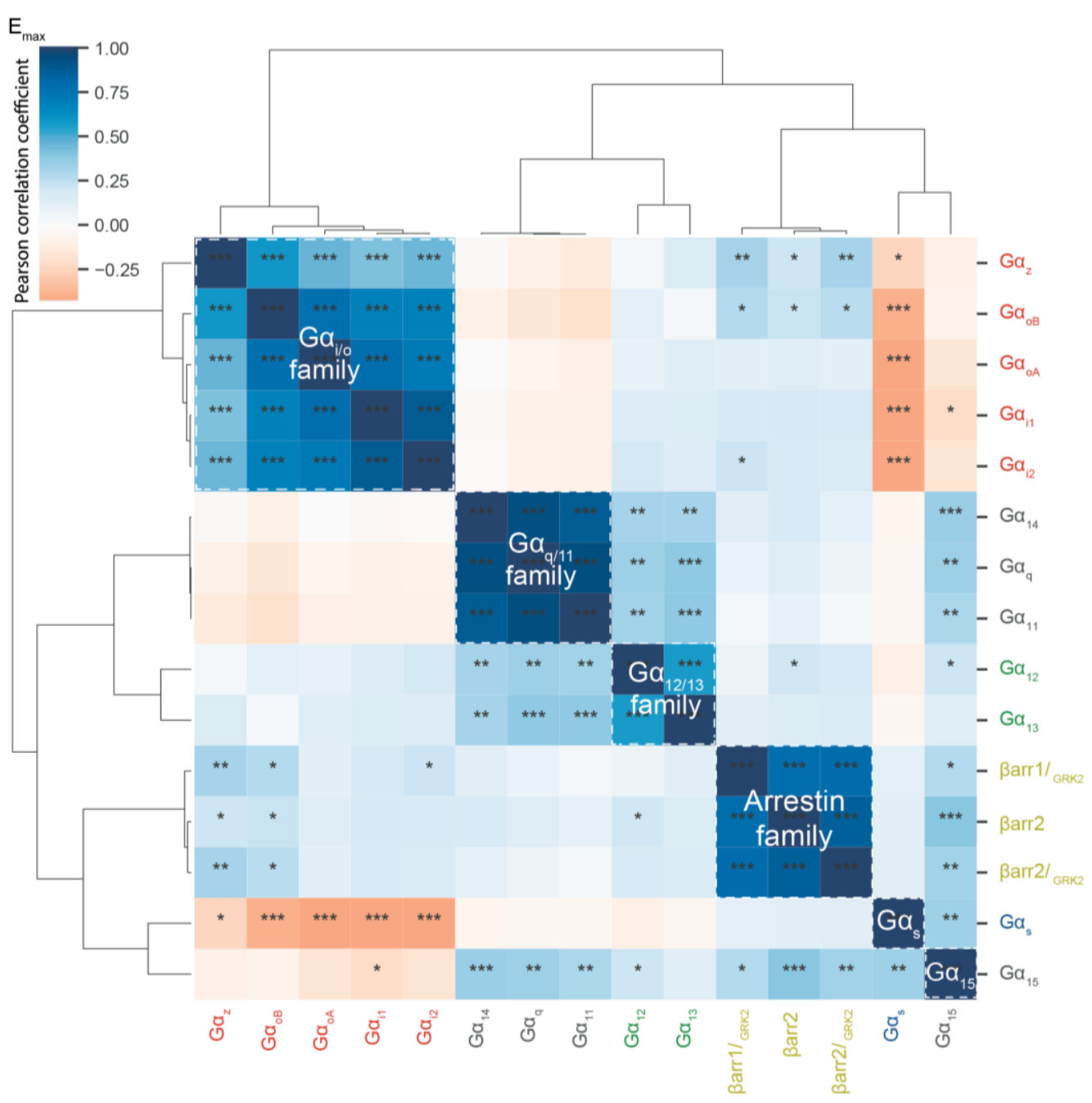

Figure 5. The EMTA ebBRET platform exposes differences in coupling selectivity within $\mathbf{G}$ proteins of the same family.

(A) Comparison of $\mathrm{G}$ protein sequence and receptor coupling profile similarities. Calculated pairwise sequence identity between two $G$ proteins in terms of their full-length similarity, Helix 5 (H5) domain, last 7 amino acids of H5 domains, and G protein barcode. G protein sequence similarities are compared with the receptor distance matrix of coupling profiles (i.e., vectors containing double normalized $E_{\max }$ values for all receptors for that pathway).

(B) Inter-effector (G protein and Barrestin) GPCR coupling correlation for 100 GPCR. Pairwise correlation of subtype double normalized $E_{\max }$ values by Pearson standard correlation coefficient, which gives a measure of the strength of the linear relationship between two pathways. Here, subtypes within $\mathrm{G}$ protein families are directly correlated (highlighted boxes) based on their pharmacological profiles. Statistically significant pairwise correlations are indicated in cells by $* p \leq 0.05 ; * * \leq 0.005$ and $* * * p \leq 0.0005$. 
A

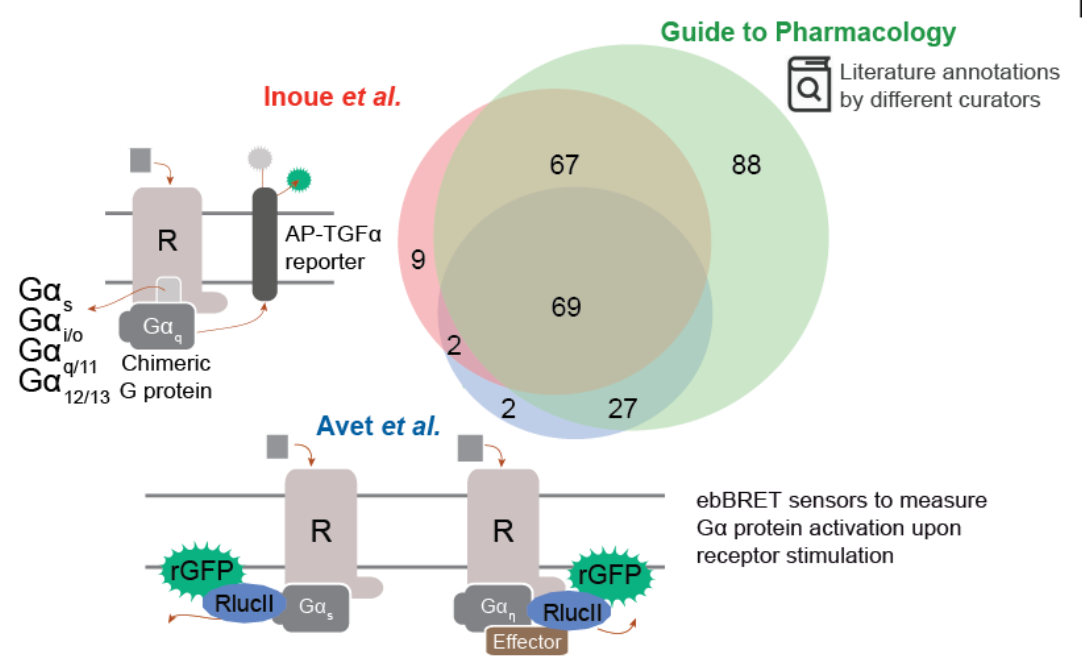

B

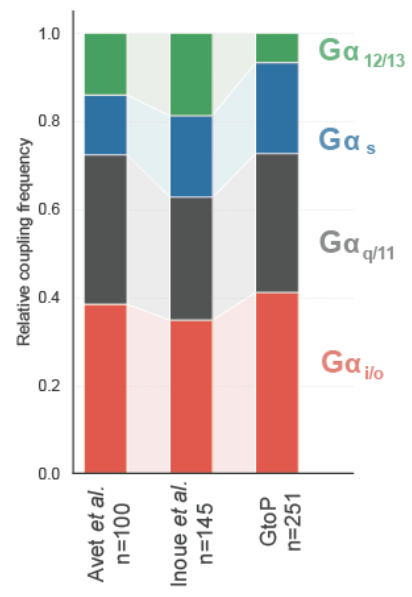

C

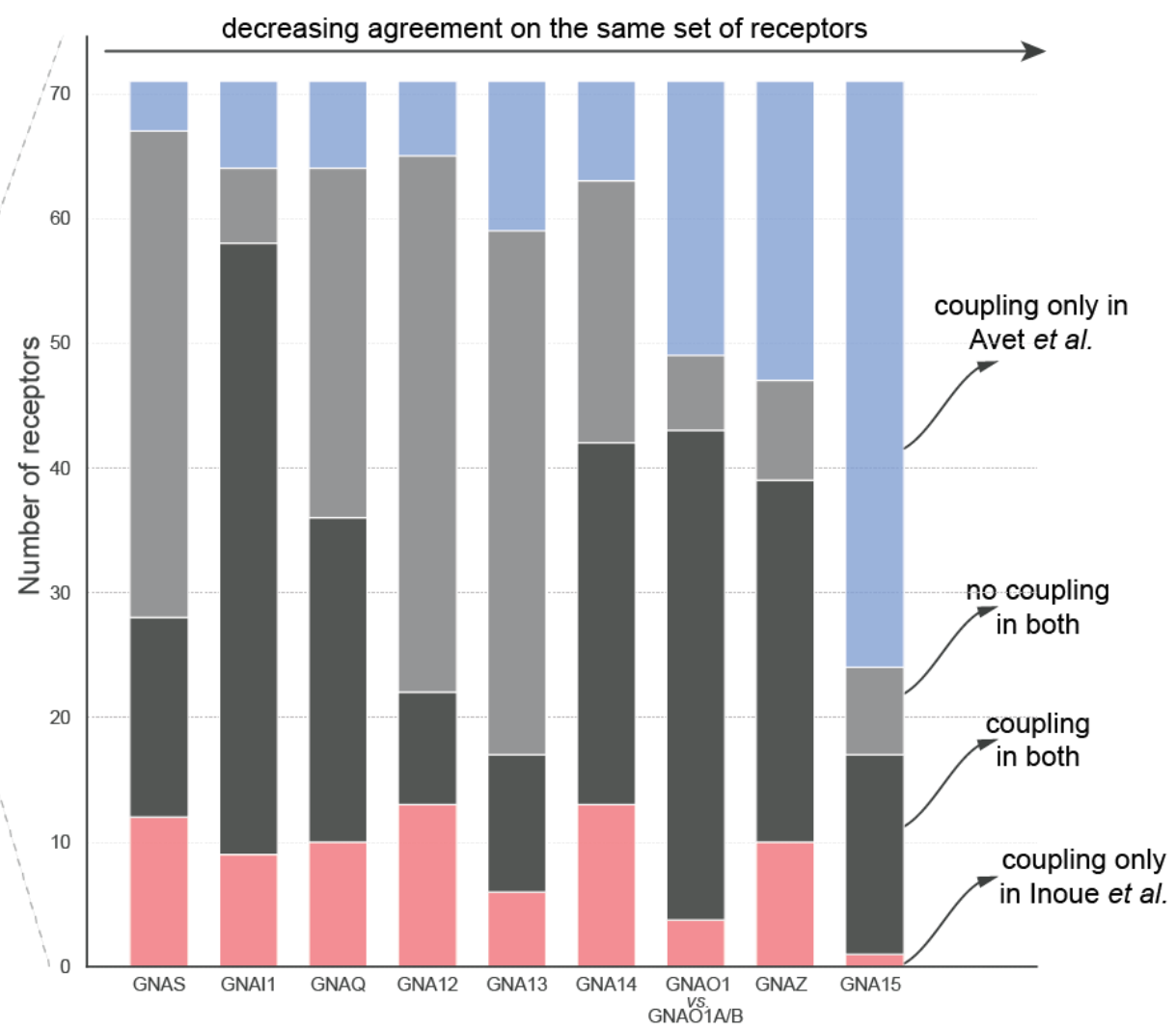

Figure 6. $G \alpha_{12 / 13}$ and $G \alpha_{15}$ activation is much more frequent than previously known.

Comparison of the G protein coupling profiles described in Avet et al. (100 GPCR), Inoue et al. (147 GPCR) (Inoue et al., 2019) and the Guide to Pharmacology database (261 GPCR, GtoPdb).

(A) Venn diagram highlighting the overlap in receptor coverage between the three coupling datasets (69 GPCR).

(B) Relative family distributions of $G$ protein couplings across datasets.

(C) G protein subtype comparison between 71 receptors assayed by both Inoue et al. and Avet et al. Data are sorted by decreasing overlap (coupling or non-coupling in both) from left to right. GNAO1A and GNAO1B from Avet et al. were combined and compared to GNAO1 from Inoue et al.

Avet's data are based on doubled normalized $E_{\max }$ values from Figure 3. 
A
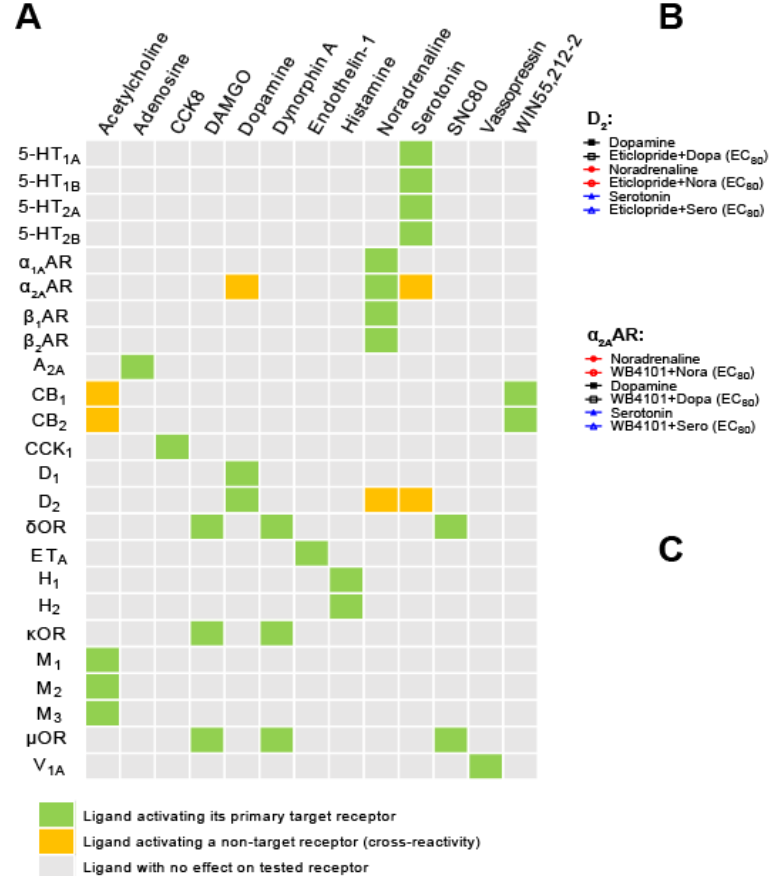
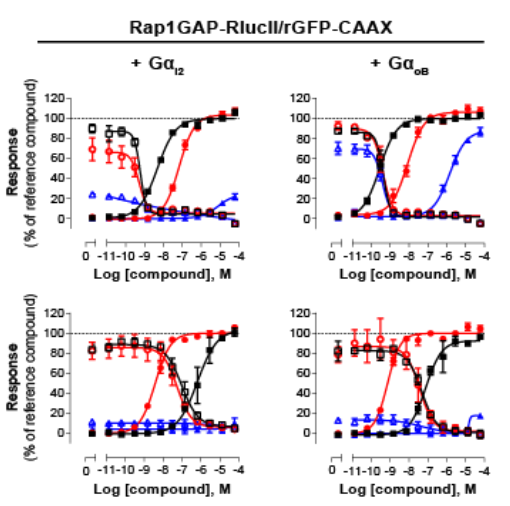

$\frac{\text { Barrestin2-Rlucll/rGFP-CAAX }}{\text { + GRK2 }}$
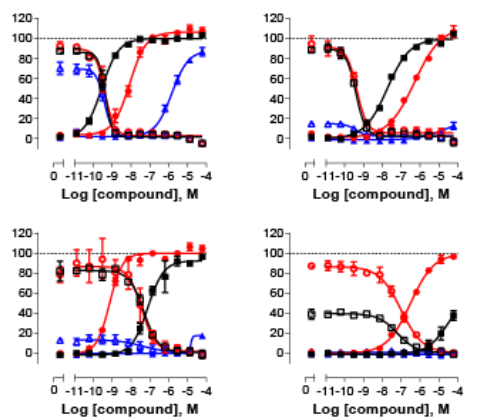

$\mathrm{CB}_{1}:$ Rap1GAP-Rlucll/rGFP-CAAX $+\mathrm{G} \alpha_{\mathrm{oB}}$
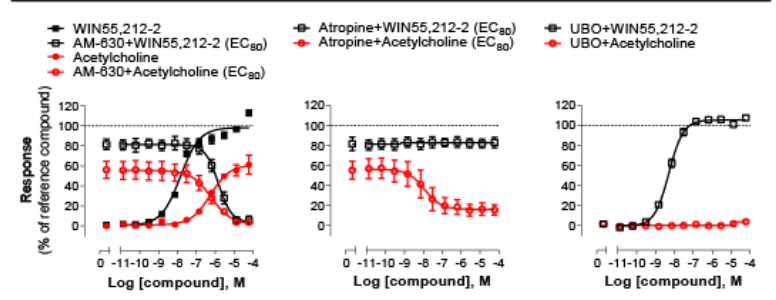

Figure 7. Detection of direct (cis) and indirect (trans) mechanisms of ligand polypharmacology using the $\mathrm{G}_{\mathrm{z}} / \mathrm{G}_{15}$ biosensor.

(A) Test of the $G_{z} / G_{15}$ biosensor on a safety target panel. ebBRET signal was measured before and after stimulation with the indicated ligand in HEK293 cells transfected with the combined $\mathrm{G}_{2} / \mathrm{G}_{15}$ biosensor and one of the 24 receptors listed.

(B) Direct (cis) activation of $D_{2}$ and $\alpha_{2 A} A R$ by others natural ligands. HEK293 cells expressing $D_{2}$ or $\alpha_{2 A} A R$ and either the $G \alpha_{i 2}, G \alpha_{o B}$, or the $\beta$ arrestin2+GRK2 sensors were stimulated into an agonist mode with increasing concentrations of the indicated ligand. For antagonist mode, cells were pretreated with increasing concentrations of the selective $D_{2}$ antagonist eticlopride or the selective $\alpha_{2 A} A R$ antagonist WB4101 before stimulation with an $E C_{80}$ concentration of the indicated ligand. Data are means \pm SEM from 3-4 independent experiments and expressed in \% of the response elicited by dopamine or noradrenaline for $D_{2}$ and $\alpha_{2 A} A R$ expressing cells, respectively.

(C) Indirect (trans) activation of $\mathrm{CB}_{1}$ by acetylcholine. HEK293 cells expressing $\mathrm{CB}_{1}$ and the Rap1GAP-Rlucll/rGFP-CAAX sensors with untagged $G \alpha_{o B}$ were stimulated into an agonist mode with increasing concentrations of the indicated ligand. For antagonist mode, same cells were pretreated or not with increasing concentrations of the $C B$ inverse agonist $A M-$ 630 (left panel) or the cholinergic antagonist atropine (central panel) before stimulation with an $\mathrm{EC}_{80}$ concentration of the indicated ligand. To evaluate the contribution of $\mathrm{G}_{\mathrm{q} / 11 \text {-coupled }}$ receptor, cells were pretreated with the $\mathrm{G}_{\mathrm{q}}$ inhibitor UBO-QIC and then stimulated with increasing concentrations of the indicated ligand (right panel). Data are means \pm SEM from 3-5 independent experiments and expressed in \% of the response elicited by WIN55,212-2. 